\title{
Vascular histone deacetylation by pharmacological HDAC inhibition
}

\author{
Haloom Rafehi, ${ }^{1,2}$ Aneta Balcerczyk, ${ }^{1,4}$ Sebastian Lunke, ${ }^{1,5}$ Antony Kaspi, ${ }^{1}$ \\ Mark Ziemann, ${ }^{1}$ Harikrishnan KN, ${ }^{1}$ Jun Okabe, ${ }^{1,3}$ Ishant Khurana, ${ }^{1}$ Jenny Ooi, ${ }^{1}$ \\ Abdul Waheed Khan, ${ }^{1}$ Xiao-Jun Du, ${ }^{1,3}$ Lisa Chang, ${ }^{1}$ Izhak Haviv, ${ }^{1,4}$ \\ Samuel T. Keating, ${ }^{1}$ Tom C. Karagiannis, ${ }^{1}$ and Assam El-Osta ${ }^{1,2,3}$ \\ ${ }^{1}$ Baker IDI Heart and Diabetes Institute, Melbourne, Victoria 3004, Australia; ${ }^{2}$ Department of Pathology, The University of Melbourne, \\ Parkville, Victoria 3010, Australia; ${ }^{3}$ Faculty of Medicine, Monash University, Victoria 3800, Australia
}

\begin{abstract}
HDAC inhibitors can regulate gene expression by post-translational modification of histone as well as nonhistone proteins. Often studied at single loci, increased histone acetylation is the paradigmatic mechanism of action. However, little is known of the extent of genome-wide changes in cells stimulated by the hydroxamic acids, TSA and SAHA. In this article, we map vascular chromatin modifications including histone H3 acetylation of lysine 9 and 14 (H3K9/14ac) using chromatin immunoprecipitation (ChIP) coupled with massive parallel sequencing (ChIP-seq). Since acetylation-mediated gene expression is often associated with modification of other lysine residues, we also examined H3K4me3 and H3K9me3 as well as changes in CpG methylation (CpG-seq). RNA sequencing indicates the differential expression of $\sim 30 \%$ of genes, with almost equal numbers being up- and down-regulated. We observed broad deacetylation and gene expression changes conferred by TSA and SAHA mediated by the loss of EP300/CREBBP binding at multiple gene promoters. This study provides an important framework for HDAC inhibitor function in vascular biology and a comprehensive description of genome-wide deacetylation by pharmacological HDAC inhibition.
\end{abstract}

[Supplemental material is available for this article.]

Histone acetylation is regulated by the opposing actions of histone acetyltransferases (HAT) and histone deacetylases (HDAC) (Marks and Xu 2009; Marks 2010). HATs catalyze the addition of acetyl groups to the $\epsilon$-amino group of lysine residues of core histones, neutralizing their positive charge. This results in a weakened interaction with the negatively charged DNA, effecting a more open, transcriptionally active, chromatin conformation (Roth et al. 2001; Smith and Denu 2009). Conversely, HDACs catalyze the removal of acetyl groups from lysine residues, resulting in a more compact, transcriptionally repressive state (Kuo and Allis 1998; Dokmanovic et al. 2007). There are 18 mammalian HDACs classified on the basis of their homology with yeast proteins (de Ruijter et al. 2003). Class I (HDAC1, HDAC2, HDAC3, and HDAC8) is predominantly localized in the nucleus with ubiquitous tissue distribution (de Ruijter et al. 2003; Gregoretti et al. 2004). Class II HDACs are further divided into IIa (HDAC4, HDAC5, HDAC7, and HDAC9) and IIb (HDAC6 and HDAC10) and shuttle between the cytoplasm and nucleus with restricted tissue distribution (Marks and Xu 2009; Marks 2010). The only member of class IV is HDAC11, which shares similarity with both class I and II enzymes (de Ruijter et al. 2003). The other HDAC enzymes, known as the sirtuins (SIRT1-7), are homologous to the yeast enzyme silent information regulator 2 (Landry et al. 2000; Tanner et al. 2000). These are nicotinamide adenine dinucleotide $\left(\mathrm{NAD}^{+}\right)$-dependent enzymes, which deacetylate lysine residues by consuming NAD ${ }^{+}$(Landry et al. 2000; Tanner et al. 2000).

Present addresses: ${ }^{4}$ Department of Molecular Biophysics, University of Lodz, 90-236 Lodz, Poland; ${ }^{5}$ Translational Genomics Laboratory, Department of Pathology, University of Melbourne, Melbourne 3010, Australia.

Corresponding author: assam.el-osta@bakeridi.edu.au

Article published online before print. Article, supplemental material, and publication date are at http://www.genome.org/cgi/doi/10.1101/gr.168781.113.
The current paradigm suggests that HDAC inhibition increases acetylation of core histones resulting in altered gene expression (Bolden et al. 2006). The current molecular mechanisms that regulate gene expression in mammalian cells are derived mainly from experiments designed to explore parallels between HDAC inhibition and lysine modification (Minucci and Pelicci 2006). HDAC inhibitors are also known to interact with nonhistone substrates, including transcription factors and coregulators, chaperones, signaling and motility mediators, as well as DNA repair proteins (Marks and Xu 2009; Marks 2010). It is clear that we do not have a complete understanding of the regulatory activities of HDACs, of which several well-characterized inhibitors function to modify lysine residues and regulate gene expression. Because the mechanisms of the HDAC inhibitor action are complicated, it is important that we have a better understanding of the pharmacological action, given the interest in developing these compounds as therapeutic agents (Marks and Breslow 2007). Recently, two HDAC inhibitors, SAHA (suberoylanilide hydroxamic acid; also known as vorinostat and Zolinza) and depsipeptide (romidepsin, Istodax) were approved by the US FDA (Thaler and Minucci 2011). The chemical structure of SAHA is very similar to that of trichostatin A (TSA), which predominantly inhibits Class I and II HDAC enzymes. The mechanism of action is thought to involve gene-activation events conferred by increased lysine acetylation.

More than just an inner lining of blood vessels, the vascular endothelium serves as an autocrine and paracrine organ regulating

(C) 2014 Rafehi et al. This article is distributed exclusively by Cold Spring Harbor Laboratory Press for the first six months after the full-issue publication date (see http://genome.cshlp.org/site/misc/terms.xhtml). After six months, it is available under a Creative Commons License (Attribution-NonCommercia 4.0 International), as described at http://creativecommons.org/licenses/by-nc/ $4.0 \%$ 
diverse processes in all vascularized tissues, including vascular permeability, angiogenesis, and the recruitment of inflammatory cells. Critical to maintaining homeostatic vascular function, endothelial cells that line the cardiovascular system are the interface between inflammation and the vessel wall and play a key role in sensing changes in blood-borne stimuli and transmitting signaling events to the underlying layers of the vessel. Endothelial dysfunction is strongly linked with inflammation in diabetes and cardiovascular disease, and the activated endothelial cell has, accordingly, emerged as a therapeutic target (Hirase and Node 2012). Identification of the multitude of transcript-coding genes potentially impacted by HDAC inhibition is paramount to a comprehensive understanding of histone acetylation and gene expression in endothelial as well as other cell types. The rapid emergence and increased accessibility of high-throughput sequencing technologies that facilitate genome and transcriptome-wide analysis has driven the generation and accumulation of large repositories of publicly accessible data. Integration of these and experimentally generated data sets greatly enhances our ability to interrogate cellular responses to HDAC inhibition. In this study, the results of a genomewide map of chromatin modifications in vascular endothelial cells are presented for the hydroxamic acids, TSA and SAHA. Our results, derived from 1.3 billion sequence reads, indicate gene expression changes subject to histone acetylation and deacetylation events.

\section{Results}

\section{Anti-inflammatory response by HDAC inhibition}

Inflammatory processes are central to cardiovascular and endothelial cell dysfunction (Pober and Sessa 2007). In primary human aortic endothelial cells (HAECs), TSA reduced (>75\%) LPS-induced monocyte adhesion (Supplemental Fig. 1A). Phorbol myristate acetate (PMA) increased the production of endothelial reactive oxygen species (ROS), which is associated with stimulating monocyte adhesion. TSA reduced PMA-induced ROS overproduction (Supplemental Fig. 1B), as well as the expression of genes associated with tumor necrosis factor (TNF) signaling (Supplemental Fig. 1C). We observed reduced TNF-dependent IL8, CCL2, and VCAM1 gene expression in TSA-stimulated HAECs (Supplemental Fig. 1D). Consistent with changes in gene expression, TSA attenuated chemokine and cytokine release, with a strong reduction of two highly expressed inflammatory proteins, CCL2 and IL6 (Supplemental Fig. 1E). Dosedependent accumulation of acetylation of lysines 9 and 14 on histone 3 (H3K9/14ac) was also observed (Supplemental Fig. 2A). TSA increased H3K4me3 and to a lesser extent H3K4me1 and H3K4me2. Quantitation shows the dose-dependent nature of TSA-induced increases in H3K9/14ac and H3K4me3 (Supplemental Fig. 2B). MTS and crystal violet cytotoxicity assays show TSA-stimulation does not significantly change cell viability at $12 \mathrm{~h}$ (Supplemental Fig. 2C). These results suggest HDAC inhibition confers anti-inflammatory responses in primary HAECs.

\section{Genome-wide maps reveal extensive deacetylation by HDAC inhibition}

While TSA is associated with histone acetylation and gene expression (Sheridan et al. 1997), more recent studies have shown localized deacetylation by sodium butyrate (Rada-Iglesias et al. 2007). To investigate genome-wide changes conferred by TSA, we generated histone modification and DNA methylation maps using ChIP-seq and CpG-seq approaches, respectively. We also integrated chromatin modifications with gene expression (mRNA-seq). To do this, we developed a method to analyze the differential distribution of sequenced tags using MACS software with a $P=10^{-5}$ cutoff (Zhang et al. 2008). Stimulated HAECs were compared to unstimulated native cells using edgeR (Robinson et al. 2010). Statistical significance was based on the Benjamini-Hochberg adjusted $P$-value $<0.05$ (Benjamini and Hochberg 1995). We observed important details about the regions of the vascular endothelial genome subject to HDAC inhibition. Increased histone acetylation was often enriched at sites with low acetylation levels before TSA stimulation (Fig. 1A). This is seen in the clustering of regions with increased acetylation with low abundance reads (upper-left quadrant). In contrast, reduced acetylation was clearly observed in the lower-right quadrant, indicating the genome is also subject to broad histone deacetylation at regions previously hyperacetylated (high tag counts), which is clearly evident by chromosome ideogram (Supplemental Fig. 2D). The number of increased and reduced $\mathrm{H} 3 \mathrm{~K} 9 / 14 \mathrm{ac}$ regions was comparable at 22,761 acetylated sites versus 23,961 deacetylated sites (adjusted $P<0.05$ ) (Fig. 1B). Compared to H3K9/14 acetylation, we found a small but significant increase in H3K4me3 (2638 versus 491) (Supplemental Table 1). We did not observe significant changes in H3K9me3 and DNA methylation, consistent with recent observations (Raynal et al. 2012). Collectively, our data indicate distinguishable acetylation and deacetylation signals in response to pharmacological HDAC inhibition.

\section{Diverse changes conferred by HDAC inhibition}

The transcription start site (TSS) is an integral element of gene regulation, and while the position of promoters in the genome can vary considerably, proximal TSS sequences are considered important sites of gene regulation (Raney et al. 2011). Since H3K9/14ac is functionally associated with gene promoters, we examined uniquely mapped tags at the TSS. Unless otherwise specified, we define promoter regions as $2.5 \mathrm{~kb}$ up- and downstream of the TSS. As shown in Figure 1C, histone deacetylation was prominent at gene promoters (deacetylation $44 \%$ versus acetylation $6 \%$ ). Since changes in H3K9/14ac might be more widespread, we examined the distribution of $\mathrm{H} 3 \mathrm{~K} 9 / 14 \mathrm{ac}$ by dividing the human genome into the proximal promoter, promoter with CpG islands (CGI), coding exons, exons, introns, 3' UTR, 5' UTR, and CpG islands, as well as intergenic regions and the whole gene. These regions were annotated using the UCSC Genome Browser (Kent et al. 2002) and expressed as the odds ratio (log to the base of $2, \log _{2}$ ) of the observed differences compared to nondifferential acetylated regions. Deacetylated regions were more likely to be found in the proximal promoter (with and without CGI), exons, and $5^{\prime}$ UTR, as well as CGI regions of genes in vascular endothelial cells (Fig. 1D). While changes in H3K4me3 were more evenly distributed between genomic features, this was less likely to occur at intergenic sites (data not shown). There were no statistically significant changes in DNA methylation or H3K9me3. Further analysis revealed histone deacetylation changes associated with mRNA and noncoding RNA (ncRNA). We found significant changes at genes that code for ncRNAs (Fig. 1E). While both increased and reduced acetylation was found at long ncRNA (lncRNA), deacetylation was prominent for tRNAs, miRNAs, and snoRNAs.

\section{Genomic methylation content defines regionalized changes}

Mammalian promoters exhibit variable CG content (Blanchette et al. 2006) and promoter regions of high CG content and

\section{Genome Research \\ www.genome.org}


A
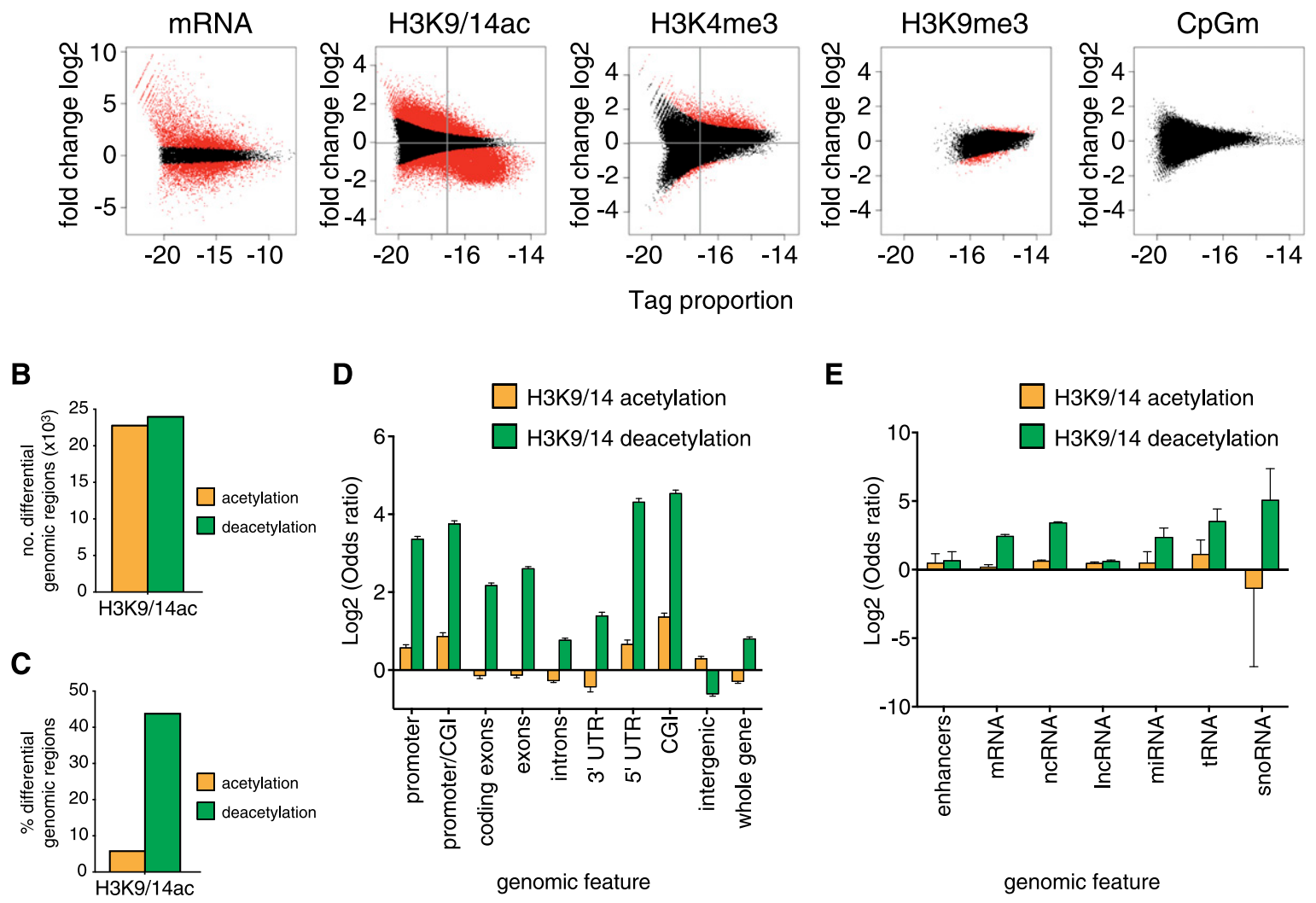

Figure 1. Biological effects of TSA in primary human vascular endothelial cells. ( $A$ ) Genome-wide distribution of chromatin marks shows significant H3K9/14 acetylation and deacetylation by HDAC inhibition. The plots shown compare the number of tags (the $\log _{2}$ of the read abundance, i.e., logConcentration determined by edgeR) versus the $\log _{2}$ fold change $\left(\log _{2} \mathrm{FC}\right)$. Regions subject to significant changes are shown in red (adjusted $P<0.05$ ), and nonsignificant changes are shown in black for TSA-stimulated HAECs. Distribution plots were divided into four quadrants for H3K9/14ac and $\mathrm{H} 3 \mathrm{~K} 4 \mathrm{me}$ 3. (B) The number of differential H3K9/14ac regions (adjusted $P<0.05$ ). Determination of differential enrichment is described in the Methods. (C) The percentage of differential H3K9/14ac regions (adjusted $P<0.05$ ) located within the gene promoter $(2.5 \mathrm{~kb}$ either side of the TSS). Enrichment of H3K9/14ac by genomic feature $(D)$ and mRNA/ncRNA $(E)$ was determined using Fisher's exact test. The $\log _{2}$ odds ratio for the genomic distribution of increased and decreased $\mathrm{H} 3 \mathrm{~K} 9 / 14 \mathrm{ac}$ is represented. Error bars represent $95 \%$ confidence intervals.

are associated with $\mathrm{CpG}$ islands. These high-CpG content promoters (HCP) are associated with ubiquitously expressed genes (Mikkelsen et al. 2007). In contrast, low-CpG content promoters (LCP) are distinguishable by selective histone modifications associated with gene expression. In TSA-stimulated cells, H3K9/14ac signals were often sheltered by DNA methylation at sites of increased (Supplemental Fig. 3A) or reduced (Supplemental Fig. 3B) histone acetylation. Because genomic methylation is generally reported to inversely correlate with gene expression, we examined the TSA response by dividing our analysis of the promoter regions of low (LCP, $n=18,946$ regions) and high (HCP, $n=2588$ regions) CpG methylation content. Fisher's exact test was used to determine the relationship between differential gene expression and H3K9/14ac changes at methylated promoters, and the results are expressed as the odds ratio $\left(\log _{2}\right)$ with $95 \%$ confidence intervals. We show that increased gene expression was more likely to occur at HCPs (Fig. $2 \mathrm{~A}$ ), and reduced expression was less likely to occur at promoters with HCPs. With respect to histone modification, TSA-stimulated changes in $\mathrm{H} 3 \mathrm{~K} 9 / 14 \mathrm{ac}$ (both increases and decreases) were less likely to occur at HCP sites (Fig. 2B). This is in striking contrast to LCP regions that were more likely to exhibit changes in H3K9/14ac. These results suggest that TSA stimulation was more likely to change $\mathrm{H} 3 \mathrm{~K} 9 / 14 \mathrm{ac}$ at LCP sites, whereas HCPs are enriched for increased changes in gene expression.

\section{Differential chromatin modifications associated with gene expression}

Next we determined if histone modifications at promoters were associated with changes in gene expression using Fisher's exact test (Table 1). Reduced gene expression was more likely to occur with decreased $\mathrm{H} 3 \mathrm{~K} 9 / 14 \mathrm{ac}$ and $\mathrm{H} 3 \mathrm{~K} 4 \mathrm{me} 3$ with odds ratios of 2.47 and 3.41, respectively, whereas up-regulated genes were more likely to be associated with increased H3K9/14ac and H3K4me3 with odds ratios of 4.80 and 6.59 , respectively. We then sought to determine whether histone modification change was correlated with gene expression. We found that $80 \%$ of the top 320 most up-regulated genes were associated with increased $\mathrm{H} 3 \mathrm{~K} 9 / 14 \mathrm{ac}$ at the gene promoter (Fig. 2C), compared to only $20 \%$ of all upregulated genes. This compares with $<10 \%$ of genes with an increase in $\mathrm{H} 3 \mathrm{~K} 9 / 14 \mathrm{ac}$ with no change in gene expression. These results suggest genes exhibiting large increases in gene expression were more likely to be enriched for acetylation. Given this relationship, we also examined the association with reduced gene expression. We found $90 \%$ of all down-regulated genes were 
A

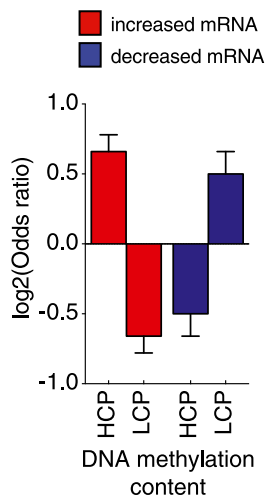

B

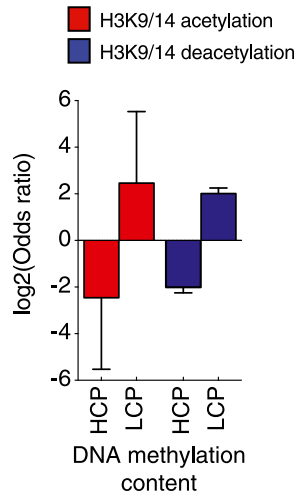

C

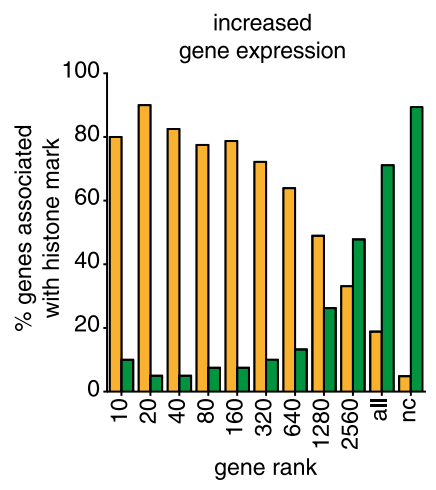

D

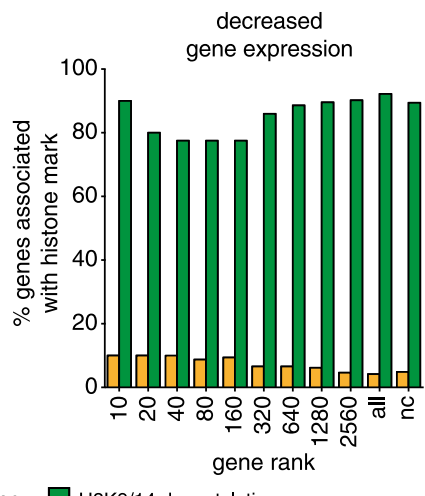

Figure 2. DNA methylation is correlated with the action of TSA at gene promoters. Fisher's exact test was used to correlate gene expression and $\mathrm{H} 3 \mathrm{~K} 9 /$ 14 ac with DNA methylation. DNA methylation regions with a concentration $\left(\log _{2}\right.$ of the average number of reads in all samples per region, i.e., logConcentration determined by edgeR) of greater than -17 were classified as high levels of methylation (HCP), and regions below -17 were defined as low DNA methylation (LCP). Error bars represent $95 \%$ confidence intervals of the $\log _{2}$ of the odds ratio. (A) Changes in mRNA expression were defined as $\log _{2} \mathrm{FC}>0$ (increased gene expression) or $\log _{2} \mathrm{FC}<0$ (decreased gene expression), and adjusted $P<0.05$. (B) Regions of acetylation were defined as log $2 \mathrm{FC}>1$ (increased acetylation) or $\log _{2} \mathrm{FC}<-1$ (decreased acetylation), adjusted $P<0.05$. Only regions with preexisting histone acetylation (cutoff of 400 reads) were included in the analyses. Correlations between increased $(C)$ and decreased $(D)$ gene expression are shown for histone acetylation (yellow) and deacetylation (green). Genes were grouped ( $x$-axis) according to the level of up- or down-regulation observed from the mRNA-seq analysis, as a cumulative rank (i.e., top 10 genes, top 20 genes, and so on, where the largest "all" category represents the whole gene set and "nc" represents no change, adjusted $P<0.05)$. The correlation is reported as the percentage of genes in each rank associated with changes in $\mathrm{H} 3 \mathrm{~K} 9 / 14 \mathrm{ac}$ at the promoter.

associated with deacetylation, including genes that do not change in expression (Fig. 2D).

HDAC inhibition is broadly associated with increased gene expression. We show that $27 \%$ of genes are differentially regulated by TSA, and we observed comparable numbers of down- $(12.6 \%)$ and up- $(14.5 \%)$ regulated transcripts using mRNA-seq (Supplemental Fig. 4A). Integration of promoter specific changes in $\mathrm{H} 3 \mathrm{~K} 9 /$ $14 \mathrm{ac}$ and H3K4me3 with changes in gene expression identified numerous significant associations (Table 2). While 12 genes were associated with bivalent marks and reduced gene expression, we found 583 genes were correlated with increased H3K9/14ac and H3K4me3. Our data also revealed key genes relevant to the endothelium, including those relevant to angiogenesis and inflammation as well as to changes in chemokine- and cytokine-related signaling (Table 3). Quantification of 20 genes associated with chemokine and cytokine response as well as endothelial function confirmed the close association between qRT-PCR and mRNAseq (Supplemental Fig. 4B). Furthermore, ChIP-seq signals for histone acetylation were validated using qRT-PCR (Supplemental Fig. 4C).

\section{HDAC inhibition alters coregulators of gene transcription}

We used gene set enrichment analyses (GSEA) to explore the potential mechanisms of histone deacetylation implicated in gene transcription (Subramanian et al. 2005). GSEA of mRNA-seq data sets identified major pathways altered by TSA (Supplemental Table 2). We identified increased expression of gene targets such as the corepressor REST, as well as those involved with channel activity. Down-regulated gene sets included those involved with chromatin and DNA binding as well as cytokine production. These results suggest that regulatory factors involved in the control of gene transcription are subject to deacetylation by HDAC inhibition. Next, we examined mRNA-seq patterns in TSA-stimulated HAECs. As shown in Table 4, increased expression of HDACs that belong to Class I (HDAC1 and HDAC3) and Class II (HDAC5), as well as Class IV (HDAC11), was observed. Interestingly, we also found reduced

Table 1. Statistical analyses of histone modification and gene expression in TSA-stimulated HAECs

\begin{tabular}{|c|c|c|c|}
\hline Histone & $P$-value ${ }^{a}$ & Odds ratio $^{b}$ & Decreased mRNA expression \\
\hline $\begin{array}{l}\uparrow \mathrm{H} 3 \mathrm{~K} 9 / 14 \mathrm{ac} \\
\downarrow \mathrm{H} 3 \mathrm{~K} 9 / 14 \mathrm{ac} \\
\uparrow \mathrm{H} 3 \mathrm{~K} 4 \mathrm{me} 3 \\
\downarrow \mathrm{H} 3 \mathrm{~K} 4 \mathrm{me} 3\end{array}$ & $\begin{array}{l}4.64 \times 10^{-45} \\
9.38 \times 10^{-71} \\
9.80 \times 10^{-124} \\
5.20 \times 10^{-3}\end{array}$ & $\begin{array}{l}0.39 \\
2.47 \\
0.17 \\
3.41\end{array}$ & $\begin{array}{l}\text { Increased } \mathrm{H} 3 \mathrm{~K} 9 / 14 \mathrm{ac} \text { less likely to occur in down-regulated genes } \\
\text { Decreased } \mathrm{H} 3 \mathrm{~K} 9 / 14 \mathrm{ac} \text { more likely to occur in down-regulated genes } \\
\text { Increased } \mathrm{H} 3 \mathrm{~K} 4 \mathrm{me} 3 \text { less likely to occur in down-regulated genes } \\
\text { Decreased } \mathrm{H} 3 \mathrm{~K} 4 \mathrm{me} 3 \text { more likely to occur in down-regulated genes }\end{array}$ \\
\hline Histone & $P$-value ${ }^{a}$ & Odds ratio $^{b}$ & Increased mRNA expression \\
\hline $\begin{array}{l}\uparrow \mathrm{H} 3 \mathrm{~K} 9 / 14 \mathrm{ac} \\
\downarrow \mathrm{H} 3 \mathrm{~K} 9 / 14 \mathrm{ac} \\
\uparrow \mathrm{H} 3 \mathrm{~K} 4 \mathrm{me} 3 \\
\downarrow \mathrm{H} 3 \mathrm{~K} 4 \mathrm{me} 3\end{array}$ & $\begin{array}{c}1.76 \times 10^{-218} \\
3.04 \times 10^{-251} \\
0 \\
3.75 \times 10^{-2}\end{array}$ & $\begin{array}{l}4.80 \\
0.26 \\
6.59 \\
0.25\end{array}$ & $\begin{array}{l}\text { Increased H3K9/14ac more likely to occur in up-regulated genes } \\
\text { Decreased } \mathrm{H} 3 \mathrm{~K} 9 / 14 \mathrm{ac} \text { less likely to occur in up-regulated genes } \\
\text { Increased } \mathrm{H} 3 \mathrm{~K} 4 \mathrm{me} 3 \text { more likely to occur in up-regulated genes } \\
\text { Decreased H3K4me3 less likely to occur in up-regulated genes }\end{array}$ \\
\hline
\end{tabular}

${ }^{a}$ Calculated using Fisher's exact test of differentially regulated genes and histone modification.

${ }^{b}$ Odds ratio $<1$ indicates an inverse correlation. 
Table 2. Changes in chromatin marks associated with gene expression in TSA-stimulated HAECs

\begin{tabular}{|c|c|c|c|c|c|}
\hline & Bivalent & H3K9/14ac & H3K4me3 & $P$-value & Odds ratio ${ }^{a}$ \\
\hline \multicolumn{6}{|c|}{ Down-regulated genes (RNA-seq) } \\
\hline Decreased H3K9/14ac & 12 & 4821 & - & $4.06 \times 10^{-3}$ & 10.7 \\
\hline Decreased H3K4me3 & 12 & - & - & 0.14 & - \\
\hline \multicolumn{6}{|c|}{ Up-regulated genes (RNA-seq) } \\
\hline Increased H3K9/14ac & 583 & 558 & - & $5.61 \times 10^{-32}$ & 8.89 \\
\hline Increased H3K4me3 & 583 & - & 824 & $1.24 \times 10^{-6}$ & 2.95 \\
\hline
\end{tabular}

Bivalent marks include $\mathrm{H} 3 \mathrm{~K} 9 / 14 \mathrm{ac}$ and $\mathrm{H} 3 \mathrm{~K} 4 \mathrm{me} 3$.

${ }^{a}$ Odds ratio is the association of bivalent modifications and gene expression change.

expression of HATs, including the functionally and structurally related CREBBP and EP3OO (Liu et al. 2008). Integrated ENCODE ChIP-seq data sets (Raney et al. 2011) with GSEA revealed deacetylation of genes associated with chromatin and DNA binding as well as coregulatory factors (Fig. 3A). GSEA revealed a strong association with EP300 and histone deacetylation at promoters (Fig. 3B). Based on these results, we hypothesized that gene suppression was subject to reduced HAT binding mediated by TSA. To test this, we used the EP300/CREBBP-specific inhibitor, C646, to examine the role of EP300/CREBBP on gene expression (Gao et al. 2013). A protein immunoblot shows that C646 attenuated TSAinduced histone acetylation (Supplemental Fig. 5). In addition, we confirm reduced expression of genes such as $B M X, P A L M D$, and IL6 using the EP300/CREBBP inhibitor C646 (Fig. 3C). We also note that $\mathrm{C} 646$ does not change the expression of several genes. For example, CCL2 was independent of EP300/CREBBP activity, whereas the activation of STAC2 and IRS2 was dependent on EP300/CREBBP inhibition by C646.

Table 3. Endothelial-specific signature in TSA-stimulated cells

\begin{tabular}{|c|c|c|c|c|c|c|c|}
\hline \multicolumn{4}{|c|}{ Increased gene expression } & \multicolumn{3}{|c|}{ Modification at TSS } & \multirow{2}{*}{$\begin{array}{c}\text { Description } \\
\text { Endothelial and other cell functions }\end{array}$} \\
\hline Gene & Accession & Adj. $P$-value & FC & Н3К9/14ac & H3K4me3 & CpGm & \\
\hline STC1 & NM_003155 & $2.59 \times 10^{-135}$ & +229.1 & $\uparrow$ & $\uparrow$ & nc & Blocks TNF permeability \\
\hline CRISPLD2 & NM_031476 & $1.48 \times 10^{-124}$ & +222.9 & $\uparrow$ & $\uparrow$ & nc & $\begin{array}{l}\text { LPS-binding protein regulates endotoxin } \\
\text { function }\end{array}$ \\
\hline$C K B$ & NM_001823 & $8.15 \times 10^{-121}$ & +694.6 & $\uparrow$ & $\uparrow$ & nc & Required for thrombin receptor signaling \\
\hline TNFSF9 & NM_003811 & $3.26 \times 10^{-105}$ & +177.3 & $\uparrow$ & $\uparrow$ & nc & Cytokine \\
\hline$A Q P 3$ & NM_004925 & $6.51 \times 10^{-92}$ & +98.4 & $\uparrow$ & $\uparrow$ & $\mathrm{nc}$ & $\begin{array}{l}\text { Negative regulator of endothelial } \\
\text { differentiation }\end{array}$ \\
\hline CELSR2 & NM_001408 & $1.09 \times 10^{-64}$ & +46.2 & $\uparrow$ & $\uparrow$ & $\mathrm{nc}$ & $\begin{array}{l}\text { Cadherin/EGF contact mediated } \\
\text { communication }\end{array}$ \\
\hline SORT1 & NM_002959 & $3.16 \times 10^{-61}$ & +17.5 & nc & $\uparrow$ & nc & Cardiovascular risk locus 1p13.3 \\
\hline EFNA3 & NM_004952 & $3.69 \times 10^{-60}$ & +41.4 & nc & $\uparrow$ & nc & $\begin{array}{l}\text { Regulation of angiogenesis and VEGFA } \\
\text { signaling }\end{array}$ \\
\hline MAPK8IP1 & NM_005456 & $3.18 \times 10^{-59}$ & +36.5 & $\uparrow$ & $\uparrow$ & nc & MAPK-pathway, type 2 diabetes candidate \\
\hline CPA4 & NM_001163446 & $3.68 \times 10^{-58}$ & +18.9 & $\uparrow$ & $\uparrow$ & nc & $\begin{array}{l}\text { Histone hyperacetylation pathway (transcript } \\
\text { variant 2) }\end{array}$ \\
\hline DUSP4 & NM_004419 & $1.77 \times 10^{-56}$ & +14.4 & $\uparrow$ & $\uparrow$ & nc & TNF induced regulation and MAPK-pathway \\
\hline CPA4 & NM_016352 & $3.97 \times 10^{-56}$ & +18.3 & $\uparrow$ & $\uparrow$ & nc & $\begin{array}{l}\text { Histone hyperacetylation pathway (transcript } \\
\text { variant 1) }\end{array}$ \\
\hline H1FO & NM_005318 & $4.15 \times 10^{-55}$ & +13.7 & $\mathrm{nc}$ & $\uparrow$ & nc & Nucleosome structure \\
\hline$B A I A P 2$ & NM_017450 & $3.96 \times 10^{-52}$ & +28.2 & $\uparrow$ & $\uparrow$ & nc & Negative regulator of angiogenesis \\
\hline \multicolumn{4}{|c|}{ Decreased gene expression } & \multicolumn{3}{|c|}{ Modification at TSS } & Description \\
\hline Gene & Accession & Adj. P-value & FC & H3К9/14ac & H3K4me3 & CpGm & Endothelial and other cell functions \\
\hline PALMD & NM_017734 & $1.11 \times 10^{-94}$ & -76.1 & $\downarrow$ & $\downarrow$ & $\mathrm{nc}$ & Membrane dynamics \\
\hline TNFSF4 & NM_003326 & $1.98 \times 10^{-87}$ & -60.1 & $\downarrow$ & $\downarrow$ & nc & Cytokine \\
\hline CLEC14A & NM_175060 & $4.34 \times 10^{-81}$ & -32.4 & $\downarrow$ & nc & nc & Pro-angiogenic \\
\hline NRP1 & NM_003873 & $1.30 \times 10^{-77}$ & -24.1 & $\downarrow$ & nc & nc & VEGFA-stimulation, endothelial cell migration \\
\hline NNMT & NM_006169 & $1.74 \times 10^{-70}$ & -28.4 & $\downarrow$ & nc & nc & S-adenosyl methionine, methyl donor \\
\hline$B M X$ & NM_001721 & $3.23 \times 10^{-65}$ & -38.9 & $\downarrow$ & nc & nc & Transduction of VEGFA (transcript variant 2) \\
\hline HMGA2 & NM_003483 & $9.19 \times 10^{-65}$ & -29.0 & $\downarrow$ & nc & nc & Angiogenesis \\
\hline$B M X$ & NM_203281 & $1.09 \times 10^{-64}$ & -38.3 & $\downarrow$ & nc & nc & Transduction of VEGFA (transcript variant 1) \\
\hline SULT1B1 & NM_014465 & $2.10 \times 10^{-53}$ & -23.9 & $\downarrow$ & nc & nc & RORA mediated inflammation \\
\hline TRIM22 & NM_006074 & $6.48 \times 10^{-51}$ & -19.2 & $\downarrow$ & nc & nc & Endothelial cell activation and inflammation \\
\hline HTR1B & NM_000863 & $5.76 \times 10^{-50}$ & -21.3 & $\downarrow$ & nc & nc & Angiogenesis \\
\hline IL1RL1 & NM_003856 & $2.64 \times 10^{-49}$ & -12.8 & $\downarrow$ & nc & nc & Angiogenesis and vascular permeability \\
\hline$B C L 6 B$ & NM_181844 & $1.39 \times 10^{-48}$ & -13.3 & $\downarrow$ & nc & nc & Mediates VEGFR-signaling in angiogenesis \\
\hline TNFRSF10D & NM_003840 & $4.54 \times 10^{-48}$ & -10.7 & $\downarrow$ & $\downarrow$ & nc & TNF-superfamily member \\
\hline
\end{tabular}

$(\uparrow)$ Increased, ( $\downarrow$ ) decreased, (nc) no change conferred by TSA stimulation, (FC) fold change, (CpGm) CpG methylation. 
Table 4. HDAC inhibition alters coregulators of gene transcription

\begin{tabular}{|c|c|c|c|c|c|c|c|}
\hline \multicolumn{4}{|c|}{ Gene expression changes } & \multicolumn{3}{|c|}{ Modification at TSS } & \multirow{2}{*}{$\frac{\text { Name and description }}{\text { Description }}$} \\
\hline Gene & Accession & Adj. $P$-value & FC & H3K9/14ac & H3K4me3 & $\mathrm{CpGm}$ & \\
\hline HDAC5 & NM_001015053 & $2.03 \times 10^{-17}$ & +5.21 & $\downarrow$ & $\uparrow$ & $\mathrm{nc}$ & Histone deacetylase 5 \\
\hline HDAC3 & NM_003883 & $6.02 \times 10^{-23}$ & +4.96 & $\downarrow$ & $\uparrow$ & $\mathrm{nc}$ & Histone deacetylase 3 \\
\hline HDAC11 & NM 024827 & $2.38 \times 10^{-4}$ & +2.33 & $\downarrow$ & $\uparrow$ & $\mathrm{nc}$ & Histone deacetylase 11 \\
\hline HDAC1 & NM 004964 & $1.59 \times 10^{-6}$ & +2.11 & 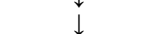 & $\uparrow$ & $\mathrm{nc}$ & Histone deacetylase 1 \\
\hline$H D A C 7$ & NM_015401 & $1.64 \times 10^{-7}$ & -2.58 & $\downarrow$ & $\mathrm{nc}$ & $\mathrm{nc}$ & Histone deacetylase 7 \\
\hline KAT2A & NM_021078 & $4.94 \times 10^{-4}$ & -0.95 & $\downarrow$ & $\mathrm{nc}$ & $\mathrm{nc}$ & Histone acetyltransferase $2 \mathrm{~A}$ \\
\hline KAT2B & NM 003884 & $2.29 \times 10^{-2}$ & -0.75 & $\downarrow$ & $\mathrm{nc}$ & $\mathrm{nc}$ & Histone acetyltransferase $2 \mathrm{~B}$ \\
\hline KAT5 & NM 006388 & $9.34 \times 10^{-3}$ & -2.91 & $\downarrow$ & $\mathrm{nc}$ & $\mathrm{nc}$ & Histone acetyltransferase 5 \\
\hline KAT6B & NM_012330 & $7.67 \times 10^{-8}$ & -2.91 & $\downarrow$ & $\mathrm{nc}$ & $\mathrm{nc}$ & Histone acetyltransferase $6 \mathrm{~B}$ \\
\hline CREBBP & NM_001079846 & $5.11 \times 10^{-10}$ & -2.99 & $\downarrow$ & $\mathrm{nc}$ & $\mathrm{nc}$ & CREB binding protein \\
\hline EP300 & NM_001429 & $1.12 \times 10^{-3}$ & -1.68 & $\downarrow$ & $\mathrm{nc}$ & $\mathrm{nc}$ & E1A binding protein p300 \\
\hline NCOA6 & NM 014071 & $8.83 \times 10^{-7}$ & -2.25 & $\downarrow$ & $\mathrm{nc}$ & nc & Nuclear receptor coactivator 6 \\
\hline NCOAS & NM_020967 & $1.93 \times 10^{-7}$ & -2.39 & $\downarrow$ & $\mathrm{nc}$ & $\mathrm{nc}$ & Nuclear receptor coactivator 5 \\
\hline NCOA2 & NM_006540 & $1.82 \times 10^{-5}$ & -2.62 & $\downarrow$ & $\mathrm{nc}$ & $\mathrm{nc}$ & Nuclear receptor coactivator 2 \\
\hline SMYD2 & NM 020197 & $2.69 \times 10^{-11}$ & -3.56 & $\downarrow$ & $\mathrm{nc}$ & nc & SMYD family member 2 \\
\hline SMYD3 & NM 001167740 & $1.46 \times 10^{-7}$ & +2.69 & $\downarrow$ & $\mathrm{nc}$ & $\mathrm{nc}$ & SMYD family member 3 \\
\hline SMYD5 & NM_006062 & $3.74 \times 10^{-7}$ & -2.53 & $\downarrow$ & $\mathrm{nc}$ & $\mathrm{nc}$ & SMYD family member 5 \\
\hline SUV39H1 & NM_003173 & $5.45 \times 10^{-11}$ & -3.81 & $\downarrow$ & $\mathrm{nc}$ & $\mathrm{nc}$ & Suppressor of variegation 3-9 homolog 1 \\
\hline SUV42OH1 & NM 017635 & $6.29 \times 10^{-4}$ & -2.27 & $\downarrow$ & $\mathrm{nc}$ & $\mathrm{nc}$ & Suppressor of variegation $4-20$ homolog 1 \\
\hline NSD1 & NM 172349 & $7.43 \times 10^{-16}$ & -3.78 & $\downarrow$ & $\mathrm{nc}$ & $\mathrm{nc}$ & Nuclear receptor binding SET domain protein 1 \\
\hline SETD1B & NM_015048 & $2.71 \times 10^{-14}$ & -4.26 & $\downarrow$ & $\mathrm{nc}$ & $\mathrm{nc}$ & SET domain containing $1 \mathrm{~B}$ \\
\hline SETD7 & NM_030648 & $4.16 \times 10^{-28}$ & -6.06 & $\downarrow$ & $\mathrm{nc}$ & $\mathrm{nc}$ & SET domain containing 7 \\
\hline
\end{tabular}

$(\uparrow)$ Increased, ( $\downarrow$ ) decreased, (nc) no change conferred by TSA stimulation, (FC) fold change, (CpGm) CpG methylation.

We hypothesized that inhibition of EP300/CREBBP activity was associated with gene suppression mediated by HDAC inhibition. Consistent with this idea, C646 alleviates TSA-dependent suppression of BMX and PALMD as well as IL6 and NOS3 (Fig. 3D). The expression of STAC2 is dependent on TSA-mediated histone acetylation. We show that C646 attenuated TSA-dependent expression of STAC2, consistent with the idea that EP300/CREBBP activity is required for gene expression (Fig. 3E). ChIP was performed to determine whether TSA changes the interaction of CREBBP on target genes. The release of CREBBP binding on BMX and IL6 genes was consistent with histone deacetylation by TSA (Fig. 3F). We also examined the interaction of CREBBP on the STAC2 gene and observed no significant change in CREBBP binding on the promoter. While we show a role for EP300/CREBBP gene regulation following HDAC inhibition, the suppression of CCL 2 was not alleviated by C646 (Fig. 3G). These results indicate a role for EP300/CREBBP regulation of gene expression mediated by HDAC inhibition.

\section{Intersecting data sets identify deacetylation}

Following the discovery of genome-wide deacetylation in our data, we questioned why deacetylation had not been previously reported. We searched the public domain and identified ChIP-seq data sets for human $\mathrm{CD} 4^{+}$T-cells stimulated by the HDAC inhibitors, TSA and sodium butyrate (Bu) (Wang et al. 2009). While this study showed HDAC inhibition was associated with gene expression mediated by increased acetylation, the study did not report histone deacetylation. First we examined TSA-stimulated HAECs and show a tight correlation for gene expression and $\mathrm{H} 3 \mathrm{~K} 9 / 14 \mathrm{ac}$ at promoters (Fig. 4A). Next we reexamined ChIP-seq data derived from $\mathrm{CD} 4^{+} \mathrm{T}$-cells to show a strong association for increased Pol II binding (used as a proxy for changes in gene expression) and increased H3K9ac in the top 500 up-regulated genes (Fig. 4B). We observed reduced Pol II binding associated with histone deacetylation in the top 500 genes with the greatest reductions in ex- pression. Furthermore, MA plots of the H3K9ac data at $2 \mathrm{~h}$ (Supplemental Fig. 6A) and $8 \mathrm{~h}$ (Supplemental Fig. 6B) show a similar pattern of histone deacetylation that was consistent with our own analyses of primary human vascular endothelial cells. Comparison of known HAT binding sites in TSA/Bu-stimulated $\mathrm{CD} 4^{+}$T-cells show deacetylation at gene promoters (FDR Q-value < 0.05) associated with EP300 and CREBBP binding, as well as PCAF and MOF (Fig. 4C). Taken together, these results indicate that highly acetylated regions of the genome are subject to deacetylation and the release of HAT binding at promoters.

\section{SAHA confers broad deacetylation and expression changes}

Bearing structural similarity to TSA, SAHA was the first hydroxamic acid approved by the US FDA for clinical trials (Mann et al. 2007). Like TSA, SAHA stimulation results in increased histone acetylation (Supplemental Fig. 6C). We observed a strong correlation in gene expression changes (Pearson's $r=0.99$ ) (Supplemental Fig. 6D) and H3K9/14ac at gene promoters for TSA and SAHA (Pearson's $r=$ 0.99) (Supplemental Fig. 6E). Conversely, we found differences in H3K4me3 signals in response to the hydroxamic acids (Supplemental Fig. 6F). We examined the distribution of peaks and found similar changes in histone acetylation for both SAHA and TSA (Supplemental Fig. 7A). Like TSA-stimulated cells, ChIP-seq analyses of SAHA-stimulated HAECs showed genome-wide gains and losses in $\mathrm{H} 3 \mathrm{~K} 9 / 14 \mathrm{ac}$, and genomic regions with a high level of acetylation before SAHA stimulation were subject to histone deacetylation (Supplemental Fig. 7B). SAHA also conferred changes in H3K9/14ac and $\mathrm{H} 3 \mathrm{~K} 4 \mathrm{me} 3$ at specific features of the genome comparable to deacetylation changes mediated by TSA (Supplemental Fig. 7C).

Pathway analysis confirmed common gene expression changes to cytoskeletal remodeling, chemokine pathways, translation, and development for both HDAC inhibitors (Supplemental Table 3). Given that a key feature of the TSA data was the strong correlation between histone modification and gene expression, we

\section{Genome Research www.genome.org}


A

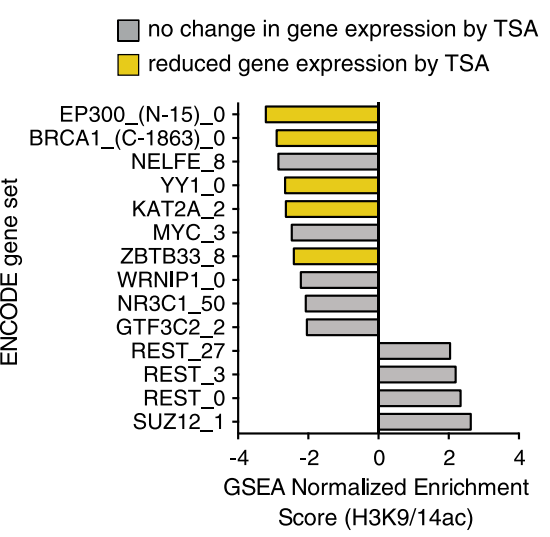

C

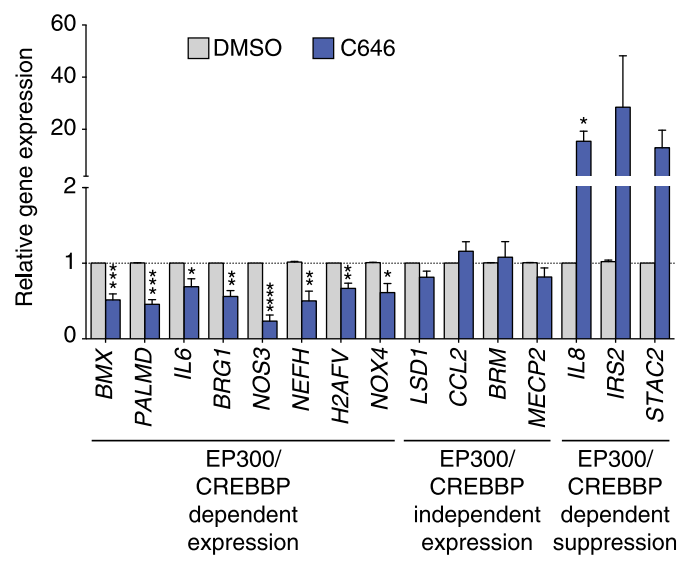

E

$\begin{array}{ll}\square \text { DMSO } & \square \text { C646 } \\ \square \text { TSA } & \square \text { TSA+C646 }\end{array}$

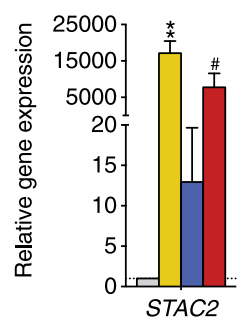

F

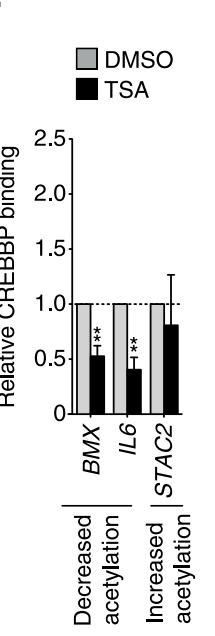

B

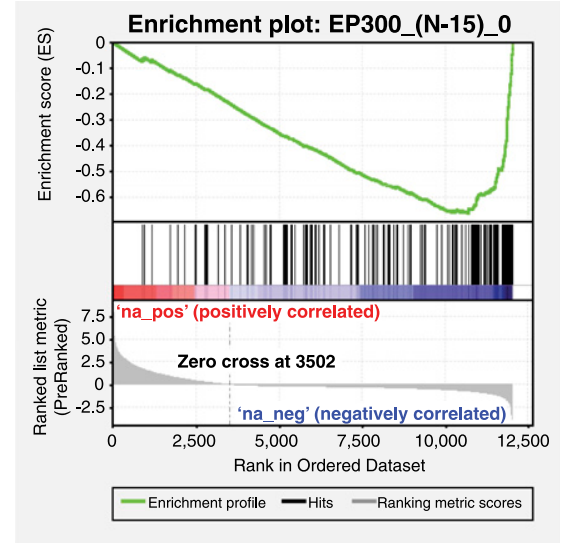

D

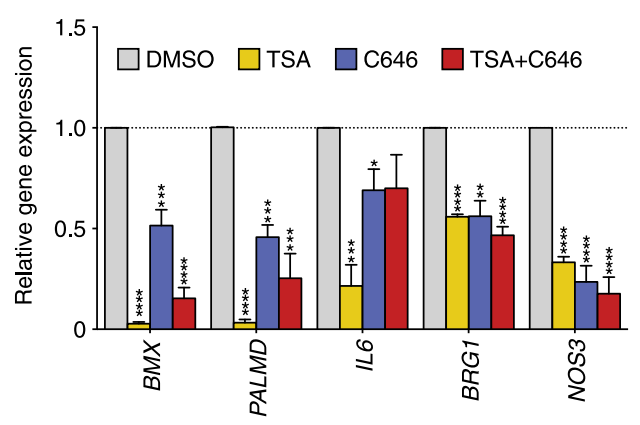

G
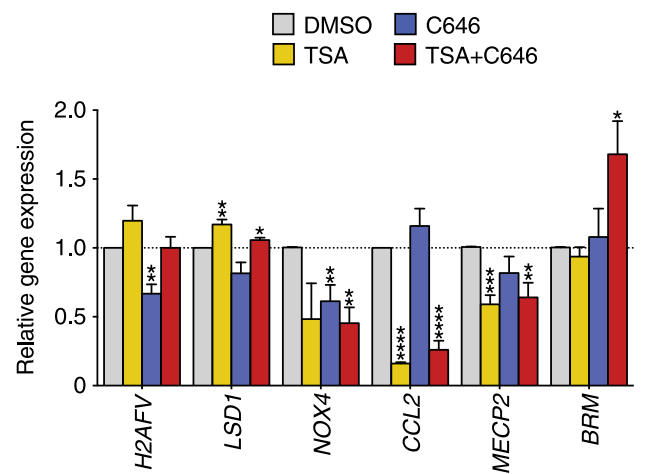

Figure 3. Loss of EP300/CREBBP HATs at gene promoters is associated with histone deacetylation. (A) GSEA identifies changes in transcription factor binding at deacetylated gene promoters using the ENCODE ChIP-seq collection of various transcription and coregulatory factors and chromatin-associated proteins (TFBS). A negative normalized enrichment score (NES) shows deacetylated gene sets, while a positive NES score indicates gene sets associated with histone acetylation. All gene sets are NOM $P$-value $<0.05$ and FDR Q-value $<0.05$ according to the standard GSEA output. Yellow bars indicate corresponding changes in gene expression of the DNA or chromatin-bound factors in TSA-stimulated HAECs (adjusted $P<0.05$ ). Numbers following the protein name represent the cell line and have been defined in the Supplemental Methods. (B) GSEA plot showing an association of EP300bound genes associated with histone deacetylation in response to TSA. Genes are ranked by changes in H3K9/14ac. (C) Gene expression changes of HAECs exposed to the C646 EP300/CREBBP inhibitor compared to DMSO control, determined by qRT-PCR. Genes are divided into three groups based on EP300/CREBBP-dependent regulation. The first group comprises expressed genes dependent on EP300/CREBBP; the second group is EP300/CREBBPindependent genes; and the third group is suppressed genes dependent on EP300/CREBBP. All data, $n=4$, except for IL8 and IRS2, $n=3$. (D,E) qRT-PCR was performed in TSA-stimulated HAECs $(500 \mathrm{nM}, 12 \mathrm{~h}), \mathrm{C} 646(20 \mu \mathrm{M}, 15 \mathrm{~h})$, and a combination of both C646 and TSA (C646: $20 \mu \mathrm{M}$, $15 \mathrm{~h}$; TSA: 500 $\mathrm{nM}, 12 \mathrm{~h}$ ). All changes in expression (TSA, C646, TSA + C646) are relative to the DMSO control. Gene expression was determined by normalizing against HPRT1. TSA-stimulated changes in gene expression are shown for genes with promoters associated with decreased $(D)$ and increased $(E)$ histone acetylation. ( $($ ) ChIP analysis was performed using anti-CREBBP antibody in TSA-stimulated HAECs (TSA: $500 \mathrm{nM}$ for $12 \mathrm{~h}$ ). (G) TSA-dependent changes in gene expression regulated by the C646 EP300/CREBBP inhibitor. Error bars represent SEM. For DMSO-, TSA-, and C646-treated cells, $n=4$. For TSA + C646 treated cells, $n=3$. For CREBBP ChIP, $n=3 .\left(^{*}\right) P<0.05,\left({ }^{* *}\right) P<0.005,\left({ }^{* *}\right) P<0.0005,\left({ }^{* * *}\right) P<0.0001,(\#) P<0.06$, unpaired $t$-test. 
A

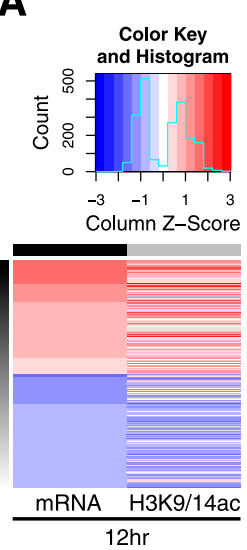

TSA (HAECs)
B
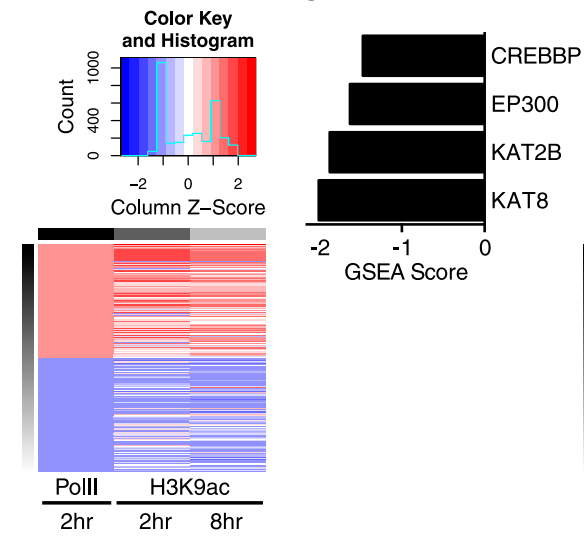

TSA+Bu (CD4+)
D

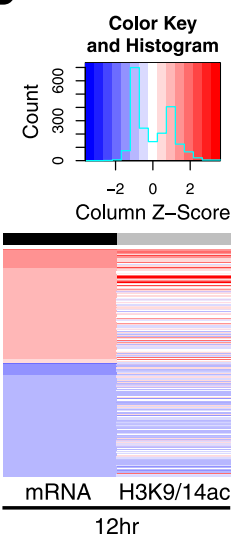

SAHA (HAECs)
E

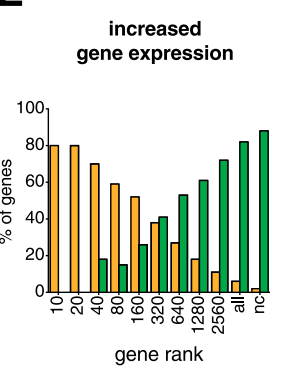

F

decreased gene expression

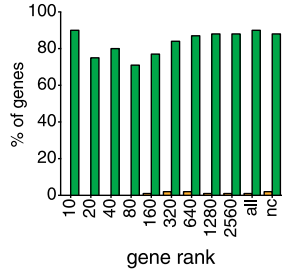

$\square \mathrm{H} 3 \mathrm{~K} 9 / 14$ acetylation

$\square \mathrm{H} 3 \mathrm{~K} 9 / 14$ deacetylation

Figure 4. Genome-wide deacetylation using HDAC inhibitors. $(A)$ Heat map showing gene expression (adjusted $P<0.05$ ) and corresponding histone acetylation changes. HAECs were stimulated with $500 \mathrm{nM} \mathrm{TSA}$ for $12 \mathrm{~h}$, and the corresponding changes in H3K9/14ac (ChIP-seq) at the promoter region were intersected with gene expression (mRNA-seq). (Red) Increases in gene expression and histone acetylation; (blue) corresponding decreases. (B) Heat map of changes in gene expression, based on Pol II ChIP-seq, in CD4+ T-cells stimulated with $100 \mathrm{ng} / \mathrm{mL}$ TSA and $2 \mathrm{mM}$ sodium butyrate for $2 \mathrm{~h}$, and corresponding changes in H3K9ac (at 2 and 8 h). Data derived from GEO (Series ID: GSE15735). (C) Normalized enrichment scores derived from GSEA showing the association of HATs in native CD4 ${ }^{+}$T-cells (determined by ChIP-seq) and changes in acetylation following $8 \mathrm{~h}$ stimulation with $100 \mathrm{ng} / \mathrm{mL}$ TSA and $2 \mathrm{mM}$ sodium butyrate. $(D)$ Heat map showing changes in gene expression (adjusted $P<0.05)$ in SAHA-stimulated HAECs $(2 \mu \mathrm{M}, 12 \mathrm{~h})$ and corresponding changes in $\mathrm{H} 3 \mathrm{~K} 9 / 14 \mathrm{ac}$ at gene promoters. $(E, F)$ Gene expression changes are associated with $\mathrm{H} 3 \mathrm{~K} 9 / 14 \mathrm{ac}$ modification in SAHA-stimulated HAECs. Genes were ranked based on expression derived from mRNA-seq analysis. (For example, the top " $10^{\prime \prime}$ genes are shown followed by the top " 20 " genes and so on [adjusted $P<0.05$ ].) The largest category represents "all" genes and "nc" refers to no change in gene expression.

used Fisher's exact test to determine if this was indeed consistent for SAHA. The results show a striking resemblance to TSA-stimulated cells, with SAHA inducing increased H3K9/14ac and H3K4me3 tightly associated with increased gene expression (odds ratios of 2.99 and 2.27, respectively) (Supplemental Table 4). Reduced gene expression was correlated with loss of H3K9/14ac and H3K4me3 (odds ratios of 1.50 and 2.54, respectively). This close relationship between the SAHA and TSA data sets was also evident for gene expression. We observed clustering of deacetylated promoters at down-regulated genes (Fig. 4D). SAHA was also associated with increased $\mathrm{H} 3 \mathrm{~K} 9 / 14 \mathrm{ac}$ and $\mathrm{H} 3 \mathrm{~K} 4 \mathrm{me} 3$ at genes with the greatest increase in gene expression (Fig. 4E), whereas reduced gene expression was associated with deacetylation (Fig. 4F). Furthermore, SAHA increased histone acetylation of genes associated with REST and SUZ12 and reduced acetylation of genes associated with binding of BRCA1 and the HATs EP300 and KAT2A (Supplemental Fig. 7D). Consistent with our earlier observations, we found that deacetylated genes were enriched for EP300 (Supplemental Fig. 7E). This further highlights similarity in the response to TSA and SAHA stimulation in HAECs. To visualize differential acetylation impli- cated in gene expression, we examined genes important in vascular endothelial function. Increased expression of STC1 was associated with promoter H3K9/14ac following TSA and SAHA stimulation (Fig. 5A). In contrast, reduced CCL2 gene expression by TSA and SAHA was not linked with reduced H3K9/14ac (Fig. 5B). Furthermore, we found deacetylation of $\mathrm{H} 3 \mathrm{~K} 9 / 14$ at the promoters of down-regulated genes IL6 (Fig. 5C) and BMX (Fig. 5D).

\section{Proof of concept in vivo: deacetylation by HDAC inhibition}

Having demonstrated ex vivo that pharmacological HDAC inhibition confers histone deacetylation, we investigated the phenomenon in vivo. We hypothesized that vascular tissue would show the characteristics of histone deacetylation in mice. As shown in Figure 6A, TSA administration did not confer any significant changes to heart mass (control $103 \pm 4 \mathrm{mg}$ versus TSA $107 \pm 5 \mathrm{mg}$ ). To study cardiac function, noninvasive echocardiography was used to measure left ventricular (LV) dimensions end-diastole and end-systole, as well as LV fractional shortening (FS). We found no significant differences in cardiac performance between control
A

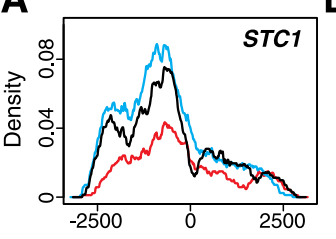

B

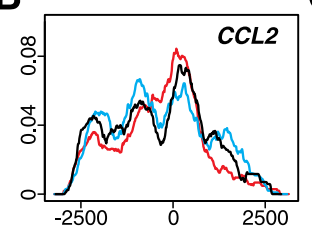

C

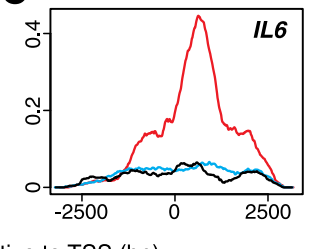

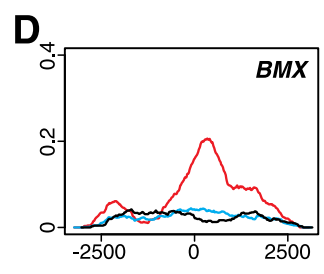

Untreated

TSA

SAHA

Figure 5. HDAC inhibition by SAHA and TSA. H3K9/14ac at promoters of genes implicated in vascular endothelial function in response to TSA and SAHA stimulation are shown. (A) Increased STC1 gene expression was associated with promoter acetylation. (B) Reduced CCL2 gene expression was not associated with changes in histone acetylation. Reduced IL6 (C) and BMX (D) gene expression were associated with histone deacetylation. H3K9/14aC profiles shown are representative of three independent experiments. Kernel density estimation bandwidth: 200.

\section{Genome Research} www.genome.org 
A

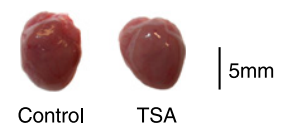

B
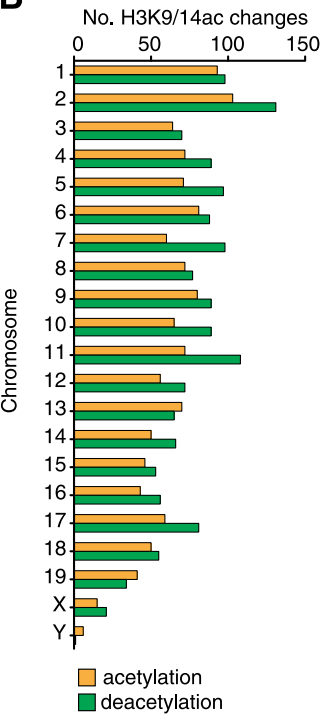

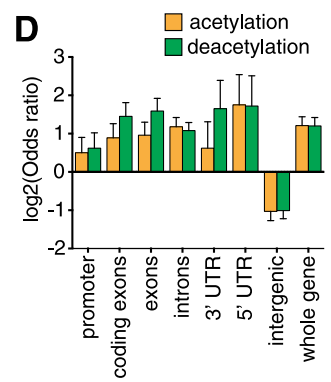

Figure 6. $\mathrm{HDAC}$ inhibition confers $\mathrm{H} 3 \mathrm{~K} 9 / 14$ acetylation and deacetylation in the heart. C57BL/6 male mice were injected subcutaneously with TSA twice daily over a 4-wk period. (A) Image of hearts from control and TSA-injected mice. (B) Ideogram of differential H3K9/14ac regions for mouse (mm9) genome. (C) $\mathrm{H} 3 \mathrm{~K} 9 / 14 \mathrm{ac}$ changes in mouse left ventricle calculated and shown as the total number of histone acetylation and deacetylation sites at intergenic regions, gene body, and promoter regions. (D) Distribution of $\mathrm{H} 3 \mathrm{~K} 9 / 14$ acetylation and deacetylation shown by genomic feature using Fisher's exact test, represented as the $\log _{2}$ odds ratio. Error bars represent $95 \%$ confidence intervals. Feature annotation is described in the Methods.

and TSA-injected mice, measured by LVDd (left ventricular dimension at diastole $4.10 \pm 0.06 \mathrm{~mm}$ versus $3.98 \pm 0.13 \mathrm{~mm}$ ) and FS (fractional shortening $38 \pm 2 \%$ versus $33 \pm 2 \%$ ). Consistent with our data for primary human cells, ChIP-seq revealed that the LV in mice was also subject to broad histone acetylation and deacetylation (Fig. 6B). Changes in H3K9/14ac signals were comparable at promoters and were more likely to occur at the gene body than at intergenic regions (Fig. 6C). We examined the distribution of $\mathrm{H} 3 \mathrm{~K} 9 / 14 \mathrm{ac}$ in specific regions of the mouse genome, namely promoters, coding exons, exons, introns, $3^{\prime}$ UTR, and 5' UTR, as well as intergenic regions. Histone acetylation changes were more likely to occur within a gene than outside a gene (Fig. 6D). In summary, the experimental results presented using pharmacological HDAC inhibitors show histone acetylation and deacetylation using ex vivo and in vivo models.

\section{Discussion}

When, in 1990, the group of Minoru Yoshida reported that trichostatin A inhibits HDAC activity, the significance of this original finding was probably underappreciated (Yoshida et al. 1990). Since this report, more than 3000 articles have been published on TSA, and 30 years later we have gained considerable insight into chromosome and histone metabolism as well as the function of HDAC enzymes using genetic approaches. While there are many roles for histone deacetylases in development and

physiology, interest has recently intensified with the introduction of HDAC inhibitors to the clinic (Haberland et al. 2009). Whereas the impact of HDAC inhibition on chromatin structure and function is unequivocal, the mode of action remains poorly understood. In this study we reveal important clues for understanding HDAC inhibition in vascular cells. The large-scale experimental results challenge traditional views that increased acetylation is the predominant event driving gene expression changes, and instead, TSA and SAHA induce genome-wide deacetylation. Our findings are particularly novel for three reasons. First, to our knowledge there are no data showing genome-wide changes comprehensively analyzed in this fashion using ex vivo and in vivo models. Second, we describe deacetylation associated with reduced EP300/CREBBP binding as a novel regulatory mechanism. Third, and most important clinically, our study is the first to demonstrate deacetylation of primary vascular cells by the proto-typical HDAC inhibitor, TSA as well as SAHA, a drug recently approved by the FDA. Taken together, the data presented argue the long-held views of HDAC inhibition may be subject to more flexibility than previously thought.

\section{Complexity of histone modification changes}

Our findings indicate TSA and SAHA significantly alter the expression of $\sim 30 \%$ of gene transcripts. While this is in accordance with previous findings using ENCODE arrays (Rada-Iglesias et al. 2007), it is not known whether deacetylation reduces gene expression (Peart et al. 2005). Almost 50\% of deacetylation events and $10 \%$ of acetylation events occur within $2.5 \mathrm{~kb}$ of the transcription start sites. We have shown that changes in histone acetylation alone do not necessarily correlate with differential gene expression. Our findings are different from observations which have typically focused on a subset of genes (Suzuki et al. 2002). While our efforts to characterize chromatin maps demonstrate deacetylation by HDAC inhibition, it was the reexamination of independent data sets that further emphasized the generality of our findings (Wang et al. 2009). Indeed, intersecting ENCODE transcription factor binding with our own data exposed important insights into the mechanisms that regulate gene expression. As for CpG methylation content, reduced gene expression was clearly associated with histone deacetylation and most likely to occur at LCPs rather than HCPs. High CpG promoters were associated with increased gene expression. The function of $\mathrm{CpG}$ methylation at target genes responsive to HDAC inhibition is poorly understood, and one explanation is that sites of histone acetylation are protected from HDAC inhibition at HCPs. Recent studies have shown that H3K4me3 and H3K79me1 are more predictive for gene activity at LCPs, whereas H3K27ac and H4K20me1 are informative for HCPs (Karlic et al. 2010). We have shown TSA-stimulated cells undergo increased gene expression at HCPs, suggesting that histone acetylation does not solely drive increased gene expression. While the explanation for differences in acetylation and deacetylation events at LCPs and HCPs is unclear, we hypothesize that other chromatin modifications are more predictive of gene expression change than DNA methylation alone.

\section{Histone deacetylation of EP300/CREBBP target genes}

The function of regulatory proteins such as histone acetyltransferases may be relevant to regulating gene expression patterns implicated in endothelial dysfunction and vascular inflammation. Central to this postulate was the reduced expression of EP300 and CREBBP genes by TSA. The EP300/CREBBP inhibitor C646 could 
attenuate changes mediated by HDAC inhibition. For example, C646 prevented TSA-dependent suppression of cytokine genes regulated by CREBBP binding. Based on these findings, we propose two modes of transcriptional regulation. First, TSA suppresses IL6 gene expression by targeting promoter deacetylation and reduced EP300/ CREBBP binding. This mode of gene suppression is consistent with observations that C646 alleviates TSA-mediated changes. Second, we believe this is distinguishable in mechanism from that of CCL2 gene regulation because TSA reduced gene expression despite treatment with C646 inhibitor. Whereas IL6 is suppressed by deacetylation, CCL2 expression is independent of deacetylation by EP300/CREBBP. Our data show that EP300/CREBBP physically interacts with gene promoters and leads to deacetylation by HDAC inhibition. With implications for regulation of gene transcription, we demonstrate EP300/CREBBP-dependent genes using C646 in TSA-stimulated cells. While EP300/CREBBP has been documented to regulate gene expression by HAT activity (Li et al. 1998, 1999), it is not clear which lysine residues other than K9/K14 are targeted in vivo. Further experiments are needed to clarify the extent of histone deacetylation by HDAC inhibition. While we have shown EP300/CREBBP binding at target genes, multiple changes mediated by pharmacological HDAC inhibition could be working in combination or independently with other transcription factors to regulate gene expression.

\section{Distinct deacetylation signals in reanalyzed data}

As for the position of genome-wide changes, reanalysis of independent data shows deacetylation at genes with high initial levels of HAT binding in $\mathrm{CD}^{+}{ }^{+} \mathrm{T}$-cells (Wang et al. 2009). Recent experimental evidence suggests HATs can be auto-acetylated, and these complexes can be recruited to many classes of DNA binding transcription factors (Blanco-Garcia et al. 2009; Hansson et al. 2009; Albaugh et al. 2011; Yang et al. 2012a,b). Indeed, HDAC inhibition is implicated in EP300 hyperacetylation, and its auto-acetylation has been shown to increase protein stability and prevent proteasomal degradation (Kim et al. 2010; Jain et al. 2012). While it is possible that acetylation changes of nonhistone proteins alter protein degradation as well as recruitment and binding to promoters, this remains an area for further investigation. With respect to pharmacological HDAC inhibition, changes in HAT binding and function only partly explain deacetylation. HATs and HDACs have been shown to interact and regulate the activity of YY1 directly by changing its acetylation status (Yao et al. 2001). Since transcriptional repression can exert an equally fundamental role in gene regulation as transcriptional activation, we hypothesize that changes in the acetylation status of DNA-binding factors such as YY1 can alter their function. Although many transcription factors and chromatin-associated proteins were associated with deacetylation, we identified only two that were associated with increased acetylation: REST, which is involved in neuronal gene repression outside the brain, and SUZ12, a critical component of the polycomb repressor complex 2, which mediates H3K27me3 and gene silencing (Coulson 2005; Margueron and Reinberg 2011). Since REST and SUZ12 participate in suppressive gene events (Montgomery et al. 2005; Nakagawa et al. 2006), further experiments are needed to clarify their role in transcription subject to HDAC inhibition.

\section{Control of vascular function}

As critical regulators of vascular wall homeostasis and signaling to inflammatory cells, endothelial cell dysfunction is strongly associated with inflammation in diabetes and associated vascular complications including cardiovascular disease. Pathways relevant to angiogenesis and inflammation, including changes in chemokine and cytokine related pathways, were identified in cells stimulated by HDAC inhibition. For example, reduced expression of $B M X$, which is implicated in VEGFA transduction, PALMD (vascular development), IL6 (cytokine and inflammation), and BRG1 (chromatin remodeling), as well as NOS3 (VEGFA-induced angiogenesis) was correlated with EP300/CREBBP activity at these genes. While HDAC inhibitors are also known to induce pleiotropic effects on HATs and other nonhistone proteins (Choudhary et al. 2009), we propose that gene expression changes are mediated by the direct loss of EP300/CREBBP-dependent acetylation.

HDAC7 is a member of the class II HDACs and is believed to control endothelial cell growth in the vasculature (Margariti et al. 2010). Our studies showed that HDAC inhibitors suppress the expression of HDAC7 in vascular endothelial cells. Genetic deletion of mouse $\mathrm{Hdac} 7$ causes embryonic lethality because of failure in endothelial cell interactions that result in dilatation and blood vessel rupture (Chang et al. 2006). In the Hdac7 null mouse, vascular disruption is accompanied with elevated expression of matrix metalloproteinase $10(\mathrm{Mmp10})$, which regulates endothelial cell interactions conferred by increased activity of the transcriptional coactivator, MEF2A. Pathological expression of matrix metalloproteinase and extracellular remodeling are implicated in cardiovascular disease. While the mechanism of MEF2A gene regulation remains uncharacterized, our data showed that TSA-stimulated HAECs suppressed HDAC7 expression, which is inversely correlated with MEF2A expression in the heart. Because HDAC inhibitors such as SAHA have entered clinical trials, it is important to determine the true physiological properties. While it is clear that pharmacological inhibitors can work in several ways that target chromatin and nonchromatin substrates, the results presented here show that the chromatin template is subject to deacetylation of histone lysine residues. Equally surprising is the efficacy of HDAC inhibitors in pathological models of cardiac failure. In the myocardium, nonhistone substrates are targets of intracellular signaling pathways that are regulated by HDAC inhibition (Song et al. 2006; Bush and McKinsey 2010). Expression of structural proteins in the mouse myocardium is dependent on MEF2 family transcription factors (Lin et al. 1997) which interact with EP300/ CREBBP for functionality (Eckner et al. 1996). Indeed, impaired activity of MEF2 proteins in the heart is associated with altered expression of contractile proteins in Ep300 null embryos (Yao et al. 1998). Given the observations reported here, we hypothesize that the response of histone deacetylation by TSA and SAHA are not necessarily under the control of a single pathway, but rather underlie the involvement of multiple signaling events. Indeed, such cross-coupling, whereby transcriptional changes are mediated by the coordination of multiple signaling pathways, is observed in Ep300 and Crebbp null animals.

\section{Proof-of-principle: histone deacetylation in vivo}

The therapeutic potential for the use of HDAC inhibitors in heart disease is well described (Olson et al. 2006). Since treatment with TSA blocks cardiac hypertrophy in models of preexisting heart failure (Kook et al. 2003; Kee et al. 2006), we examined genomewide histone acetylation changes in preclinical models. The rationale behind these experiments was twofold. First, although systemic TSA treatment is strongly predicted to increase histone acetylation, to our knowledge there are no data that comprehensively examine this phenomenon in vivo. Second, and more im-

\section{Genome Research} www.genome.org 
portant clinically, these experiments explore proof-of-concept, that is, HDAC inhibition confers strong deacetylation, which is relevant not only to the vascular endothelium and the myocardium but also because pharmacological inhibitors have entered clinical trials (Lehrman et al. 2005; Almeida et al. 2007; Mann et al. 2007). Our data highlight that the heart undergoes dramatic changes in H3K9/14 deacetylation, which are more likely to occur within a gene than outside a gene. Whether histone deacetylation of EP300/CREBBP target genes is conferred in the myocardium is a fertile area of future investigation.

\section{Conclusions}

Characterizing the vascular epigenome is important, considering that pharmacokinetics and pharmacology of HDAC inhibitors have been studied and largely determined by ADME properties (absorption, distribution, metabolism, and extraction). Vascular toxicity is critical to early drug design development or rational drug discovery. While preclinical ADME screens provide useful data, genome-wide studies are still limited. Given the poorly characterized mechanisms regulating endothelial function and inflammation, our data define major roles for transcription and coregulatory factors such as EP300/CREBBP regulating chromatin modification. Since drug development relies on improving the design of pharmacological inhibitors, determining the role of chromatin and nonchromatin targets will likely require definition of these changes to understand the mechanisms of gene regulation. The comprehensive chromatin maps described here should provide a useful framework and resource to further understand deacetylation by HDAC inhibitors.

\section{Methods}

\section{Cell culture}

Human aortic endothelial cells purchased from Lonza were cultured in endothelial cell basal growth medium-2 (EBM-2) (Lonza) containing EGM-2 growth factors, supplements (Lonza), and 10\% heat-inactivated fetal bovine serum (FBS) (Gibco). Cells used for the experiments were from passages 4-6. HAECs were stimulated with $500 \mathrm{nM}$ TSA or $2 \mu \mathrm{M}$ SAHA for $12 \mathrm{~h}$ for all mRNA-seq and ChIP-seq. For qRT-PCR, HAECs were exposed to $20 \mu \mathrm{M}$ C646 for $15 \mathrm{~h}$. For combined TSA and C646, cells were incubated to C646 for $3 \mathrm{~h}$ before stimulation with TSA for a further $12 \mathrm{~h}$.

\section{Cell viability}

Cell viability following treatment with the indicated concentrations of TSA for $12 \mathrm{~h}$ at $37^{\circ} \mathrm{C}$ was measured using the CellTiter96 Aqueous One Solution Cell Proliferation Assay (MTS) (Promega) and crystal violet staining methods, as described in the Supplemental Material.

\section{In vivo mouse mode}

C57BL/6 male mice (10-12 wk old) were injected subcutaneously twice daily at $0.6 \mathrm{mg} / \mathrm{kg} /$ day of TSA for $4 \mathrm{wk}$, as previously described (Chang et al. 2011). To study cardiac function, noninvasive echocardiography was used to measure left ventricular (LV) dimensions end-diastole and end-systole as well as LV fractional shortening (FS). The animals were killed and the LVs isolated and snap-frozen immediately for downstream molecular experiments. For gene expression, RNA isolation and cDNA synthesis were performed as previously described. LVs were pooled for one ChIP experiment with H3K9/K14 antibody (06-599, Upstate) and performed as previously described (Chang et al. 2011).

\section{Protein blotting}

Immunoblotting for acetyl-H4 (06-866, Upstate), acetyl-H3K9/14 (06-599, Millipore), H3K4me1 (39297, Active Motif), H3K4me2 (7766, Abcam), H3K4me3 (07-473, Upstate), H3K9me1 (9045, Abcam), H3K9me2 (39141, Active Motif), and H3K9me3 (8898, Abcam) was performed using histone $\mathrm{H} 3$ (05-928, Upstate) as the loading control on histones prepared under acidic conditions from TSA-stimulated HAECs, as described in the Supplemental Material.

\section{Inflammation studies}

Monocyte adhesion assay, cytokine and chemokine release assay, and PMA assay have been described in the Supplemental Methods.

\section{Chromatin immunoprecipitation}

Chromatin immunoprecipitation was performed according to the manufacturer's procedure (Upstate Biotechnology) with some modifications. Native and TSA-stimulated HAECs and mouse left ventricle (cut into fine pieces) were fixed for $10 \mathrm{~min}$ with $1 \%$ formaldehyde. Glycine $(0.125 \mathrm{M})$ solution was then added for another $10 \mathrm{~min}$. Cell pellets and left ventricle pieces were resuspended in sodium dodecyl (lauryl) sulfate (SDS) lysis buffer (1\% SDS, $10 \mathrm{mM}$ EDTA, $50 \mathrm{mM}$ Tris-HCl, $\mathrm{pH}$ 8.1) (Upstate) and a protease inhibitor cocktail (Roche Diagnostics $\mathrm{GmBH}$ ). Cells and left ventricles were sonicated to shear chromatin to 200-600 bp. Chromatin was resuspended in ChIP dilution buffer (0.01\% SDS, 1.1\% Triton X-100, 1.2 mM EDTA, 16.7 mM Tris-HCl, pH 8.0, and $167 \mathrm{mM} \mathrm{NaCl}$ ) (Upstate), and $20 \mu \mathrm{l}$ of Dynabeads Protein A (Invitrogen) were added and precleared. To the soluble chromatin fraction, antibody (H3K9/14ac, 06-599, Millipore; H3K4me3, 39159, Active Motif; H3K9me3, 8898, Abcam; CREBBP, sc-369, Santa Cruz Biotechnology) was added and incubated overnight at $4^{\circ} \mathrm{C}$. Immunoprecipitated complexes were collected with DynaMag-2 magnet (Invitrogen), washed (in the following sequence: low-salt buffer, high-salt buffer, LiCl-containing buffer, TE buffer) and eluted with $0.1 \mathrm{M} \mathrm{NaHCO}_{3}$ with $1 \%$ SDS. Protein-DNA cross-links were reversed by adding $120 \mu \mathrm{g}$ of Proteinase K (Sigma) and incubation at $62^{\circ} \mathrm{C}$ for $2 \mathrm{~h}$. DNA was recovered using a Qiagen MinElute column (Qiagen).

\section{Library construction and mRNA sequencing}

Total RNA was isolated with TRIzol (Invitrogen). Libraries were prepared according to the Illumina mRNA-seq library preparation kit (cat. \#RS-100-0801). Briefly, $8 \mu \mathrm{g}$ of total RNA was taken for mRNA isolation using poly-T oligo-attached magnetic beads. Poly-A mRNA was fragmented with the presence of divalent cations under elevated temperatures. The mRNA fragments were reverse-transcribed via SuperScript II (Invitrogen) with random primers. The second strand was synthesized with addition of RNase $\mathrm{H}$ and DNA Pol I. Double-stranded complementary DNA (dscDNA) was end-repaired, followed by $3^{\prime}$ adenylation and ligation to universal adapters. The ligated cDNA library was separated on a $2.0 \%$ agarose gel. Library cDNA fragments in the range of $200 \mathrm{bp} \pm$ $10 \mathrm{bp}$ were isolated by gel purification (Qiagen) and amplified with 15 cycles of PCR. Column-purified libraries were quantified fluorometrically and visualized by MultiNA for quality assurance. Libraries were diluted to $10 \mathrm{nM}$ and stored at $-20^{\circ} \mathrm{C}$ prior to cluster generation (also at a concentration of $6 \mathrm{pM}$ ) and 36-base se- 
quencing. Short-read sequences of 36 base pairs were generated using Illumina Pipeline 1.4. Each sequence read was aligned with the Burrows-Wheeler Aligner (BWA, version 0.6.1) against the hg19 RefSeq transcriptome, downloaded from UCSC (Li and Durbin 2010). The read count for each transcript was transformed into a matrix, with transcript ID as rows and sample name as columns. The conditions in this matrix were compared for significance using edgeR software (Robinson et al. 2010). Genes were determined as significant if the Benjamini-Hochberg adjusted $P<0.05$ (Benjamini and Hochberg 1995).

\section{Massive parallel sequencing for ChIP}

ChIP-seq libraries were prepared according to the protocols described in the Illumina ChIP-seq library preparation kit (cat. \#IP-102-1001). Briefly, $10 \mathrm{ng}$ of immunopurified DNA or genomic DNA from an input sample was end-repaired, followed by 3 ' adenylation using a Klenow fragment ( $3^{\prime}$ to $5^{\prime}$ exo minus) and ligated to universal library adapters with T-overhangs at their $3^{\prime}$ end. Ligated material was separated on a $2.0 \%$ agarose gel, and fragments in the range of 250 $350 \mathrm{bp}$ were excised and column-purified (Qiagen). A DNA library was obtained by an 18-cycle PCR amplification using Phusion DNA polymerase $\left(10 \mathrm{sec} 98^{\circ} \mathrm{C}, 30 \mathrm{sec} 65^{\circ} \mathrm{C}, 30 \sec 72^{\circ} \mathrm{C}\right)$ with oligonucleotides complementary to Illumina sequencing adapters. Column-purified libraries were quantified fluorometrically (Qubit) and visualized by MultiNA capillary electrophoresis (DNA 500 kit) for quality assurance. Libraries were diluted to $10 \mathrm{nM}$ and stored at $-20^{\circ} \mathrm{C}$ prior to cluster generation at a final DNA concentration of $6 \mathrm{pM}$. Sequencing of the first 36 nucleotides was performed on the Genome Analyzer IIx instrument (Illumina) according to the manufacturer's protocols. Short-read sequences of 36 base pairs were generated using Illumina Pipeline 1.4. These short reads were aligned with BWA (version 0.6.1) (Li and Durbin 2010) against the hg19 human genome (hg19, GRCh37, February 2009) (HAEC samples) and $\mathrm{mm} 9$ mouse genome (left ventricle) using default parameters. Regions of interest were defined by comparing each human ChIP sample against an input sample from the same condition, and the mouse H3K9/14ac ChIP against an unstimulated control, using MACS (version 1.4.1) software using default parameters (Zhang et al. 2008) with a cutoff of $P=10^{-5}$, except for the human marker H3K9me3, which was compared to the first 10,000 base pairs of genes bodies in the hg19 genome (hg19, GRCh37, February 2009). For ChIP-seq, all overlapping regions of histone modification in the TSA-stimulated and unstimulated control cells were merged to create a single list of regions as determined by MACS. The number of reads occurring in these regions was determined for each control and treatment replicate to generate a matrix of read counts. Significant differences between unstimulated and TSA-stimulated cells were determined by edgeR and trimmed using mean normalization (nondifferential sequence read count quantile threshold of 0.3 , prior. n of 20 , and $P$-value threshold for FDR filtering for family-wise error rate control of 0.05) (Robinson et al. 2010). Genomic regions were determined as significant if the Benjamini-Hochberg adjusted $P$-value $<0.05$ (Benjamini and Hochberg 1995). Data from SAHA-stimulated cells was analyzed using MACS (version 1.4.1) peak calling, by comparing each sample to the input, using default settings.

\section{Massive parallel sequencing for DNA methylation}

Genomic DNA derived from native and stimulated HAECs was fragmented to $150-200$ bp by a Diagnode sonicator and subjected to methylated DNA enrichment using the MethylMiner kit (ME10035, Invitrogen) in triplicate. Briefly, methylated DNA was captured from $500 \mathrm{ng}$ of fragmented genomic DNA via binding
MBD2 protein coupled to magnetic Dynabeads, which was incubated for $1 \mathrm{~h}$ with rotation. The methylated fragments were then eluted in three distinct subpopulations using $0.6 \mathrm{M}, 1 \mathrm{M}$, and $2 \mathrm{M}$ salt elution buffers, respectively (supplied in MethylMiner kit). Methylated DNA fragments, eluted with $2 \mathrm{M}$ salt buffer, were purified and selected for sequencing on the Illumina Genome Analyzer. Sequencing of the first $36 \mathrm{nt}$ was performed on the Genome Analyzer IIx instrument (Illumina) according to the manufacturer's protocols. Short-read sequences of 36 base pairs were generated using Illumina Pipeline 1.4. These short reads were aligned with BWA (version 0.5.9) using default parameters ( $\mathrm{Li}$ and Durbin 2010) against the hg19 human genome (hg19, GRCh37, February 2009) (HAEC samples). Regions of interest were defined by comparing each CpG-seq sample against an input sample from the same condition using MACS software (version 1.4.1) with default parameters (Zhang et al. 2008) with a cutoff of $P=10^{-5}$. Human ChIP regions were merged for each ChIP and the read counts summarized to create a matrix with region coordinates as rows and sample names as columns. The samples in this matrix were compared for significance using edgeR software (Robinson et al. 2010). Genes were determined as significant if the Benjamini-Hochberg adjusted $P$-value $<0.05$ (Benjamini and Hochberg 1995).

\section{Data access}

The mRNA-seq, ChIP-seq, and CpG-seq data used for this research have been submitted to the NCBI Gene Expression Omnibus (GEO; http://www.ncbi.nlm.nih.gov/geo/) under accession number GSE37378.

\section{Acknowledgments}

We thank Helen Kiriazis, Xiao-Ming Gao, Luciano Pirola, Andrew Siebel, and Prabhu Mathiyalagan for preparative assistance and Ross Lazarus for bioinformatics support. We also acknowledge grant and fellowship support from the Juvenile Diabetes Research Foundation International (JDRF), the Diabetes Australia Research Trust (DART), the National Health and Medical Research Council (NHMRC), and the National Heart Foundation of Australia (NHF). A.E.-O. and X.-J.D. are Senior Research Fellows supported by the NHMRC. This research was supported in part by the Victorian Government's Operational Infrastructure Support Program.

\section{References}

Albaugh BN, Arnold KM, Lee S, Denu JM. 2011. Autoacetylation of the histone acetyltransferase Rtt109. J Biol Chem 286: 24694-24701.

Almeida AM, Murakami Y, Baker A, Maeda Y, Roberts IA, Kinoshita T, Layton DM, Karadimitris A. 2007. Targeted therapy for inherited GPI deficiency. N Engl J Med 356: 1641-1647.

Benjamini Y, Hochberg Y. 1995. Controlling the false discovery rate: a practical and powerful approach to multiple testing. J R Stat Soc Ser B Methodol 57: 289-300.

Blanchette M, Bataille AR, Chen X, Poitras C, Laganiere J, Lefebvre C, Deblois G, Giguere V, Ferretti V, Bergeron D, et al. 2006. Genome-wide computational prediction of transcriptional regulatory modules reveals new insights into human gene expression. Genome Res 16: 656-668.

Blanco-Garcia N, Asensio-Juan E, de la Cruz X, Martinez-Balbas MA. 2009 Autoacetylation regulates P/CAF nuclear localization. J Biol Chem 284: 1343-1352.

Bolden JE, Peart MJ, Johnstone RW. 2006. Anticancer activities of histone deacetylase inhibitors. Nat Rev Drug Discov 5: 769-784.

Bush EW, McKinsey TA. 2010. Protein acetylation in the cardiorenal axis: the promise of histone deacetylase inhibitors. Circ Res 106: 272-284.

Chang S, Young BD, Li S, Qi X, Richardson JA, Olson EN. 2006. Histone deacetylase 7 maintains vascular integrity by repressing matrix metalloproteinase 10. Cell 126: 321-334.

\section{Genome Research}


Chang L, Kiriazis H, Gao XM, Du XJ, El-Osta A. 2011. Cardiac genes show contextual SWI/SNF interactions with distinguishable gene activities. Epigenetics 6: 760-768.

Choudhary C, Kumar C, Gnad F, Nielsen ML, Rehman M, Walther TC, Olsen JV, Mann M. 2009. Lysine acetylation targets protein complexes and co-regulates major cellular functions. Science 325: 834-840.

Coulson JM. 2005. Transcriptional regulation: cancer, neurons and the REST. Curr Biol 15: R665-668.

de Ruijter AJ, van Gennip AH, Caron HN, Kemp S, van Kuilenburg AB. 2003. Histone deacetylases (HDACs): characterization of the classical HDAC family. Biochem J 370: 737-749.

Dokmanovic M, Clarke C, Marks PA. 2007. Histone deacetylase inhibitors: overview and perspectives. Mol Cancer Res 5: 981-989.

Eckner R, Yao TP, Oldread E, Livingston DM. 1996. Interaction and functional collaboration of p300/CBP and bHLH proteins in muscle and B-cell differentiation. Genes Dev 10: 2478-2490.

Gao XN, Lin J, Ning QY, Gao L, Yao YS, Zhou JH, Li YH, Wang LL, Yu L. 2013 A histone acetyltransferase p300 inhibitor C646 induces cell cycle arrest and apoptosis selectively in AML1-ETO-positive AML cells. PLOS ONE 8: e55481.

Gregoretti IV, Lee YM, Goodson HV. 2004. Molecular evolution of the histone deacetylase family: functional implications of phylogenetic analysis. J Mol Biol 338: 17-31.

Haberland M, Montgomery RL, Olson EN. 2009. The many roles of histone deacetylases in development and physiology: implications for disease and therapy. Nat Rev Genet 10: 32-42.

Hansson ML, Popko-Scibor AE, Saint Just Ribeiro M, Dancy BM, Lindberg MJ, Cole PA, Wallberg AE. 2009. The transcriptional coactivator MAML1 regulates p300 autoacetylation and HAT activity. Nucleic Acids Res 37: 2996-3006.

Hirase T, Node K. 2012. Endothelial dysfunction as a cellular mechanism for vascular failure. Am J Physiol Heart Circ Physiol 302: H499-H505.

Jain S, Wei J, Mitrani LR, Bishopric NH. 2012. Auto-acetylation stabilizes p300 in cardiac myocytes during acute oxidative stress, promoting STAT3 accumulation and cell survival. Breast Cancer Res Treat 135: 103-114.

Karlic R, Chung HR, Lasserre J, Vlahovicek K, Vingron M. 2010. Histone modification levels are predictive for gene expression. Proc Natl Acad Sci 107: 2926-2931

Kee HJ, Sohn IS, Nam KI, Park JE, Qian YR, Yin Z, Ahn Y, Jeong MH, Bang YJ, Kim N, et al. 2006. Inhibition of histone deacetylation blocks cardiac hypertrophy induced by angiotensin II infusion and aortic banding. Circulation 113: 51-59.

Kent WJ, Sugnet CW, Furey TS, Roskin KM, Pringle TH, Zahler AM, Haussler D. 2002. The human genome browser at UCSC. Genome Res 12: 996-1006.

Kim SH, Kang HJ, Na H, Lee MO. 2010. Trichostatin A enhances acetylation as well as protein stability of $\mathrm{ER} \alpha$ through induction of p300 protein. Breast Cancer Res 12: R22.

Kook H, Lepore JJ, Gitler AD, Lu MM, Wing-Man Yung W, Mackay J, Zhou R, Ferrari V, Gruber P, Epstein JA. 2003. Cardiac hypertrophy and histone deacetylase-dependent transcriptional repression mediated by the atypical homeodomain protein Hop. J Clin Invest 112: $863-871$.

Kuo MH, Allis CD. 1998. Roles of histone acetyltransferases and deacetylases in gene regulation. BioEssays 20: 615-626.

Landry J, Sutton A, Tafrov ST, Heller RC, Stebbins J, Pillus L, Sternglanz R. 2000. The silencing protein SIR2 and its homologs are NAD-dependent protein deacetylases. Proc Natl Acad Sci 97: 5807-5811.

Lehrman G, Hogue IB, Palmer S, Jennings C, Spina CA, Wiegand A, Landay AL, Coombs RW, Richman DD, Mellors JW, et al. 2005. Depletion of latent HIV-1 infection in vivo: a proof-of-concept study. Lancet 366: 549-555.

Li H, Durbin R. 2010. Fast and accurate long-read alignment with Burrows-Wheeler transform. Bioinformatics 26: 589-595.

Li Q, Herrler M, Landsberger N, Kaludov N, Ogryzko VV, Nakatani Y, Wolffe AP. 1998. Xenopus NF-Y pre-sets chromatin to potentiate p300 and acetylation-responsive transcription from the Xenopus hsp70 promoter in vivo. EMBO J 17: 6300-6315.

Li Q, Imhof A, Collingwood TN, Urnov FD, Wolffe AP. 1999. p300 stimulates transcription instigated by ligand-bound thyroid hormone receptor at a step subsequent to chromatin disruption. EMBO J 18: 5634-5652.

Lin Q, Schwarz J, Bucana C, Olson EN. 1997. Control of mouse cardiac morphogenesis and myogenesis by transcription factor MEF2C. Science 276: $1404-1407$.

Liu X, Wang L, Zhao K, Thompson PR, Hwang Y, Marmorstein R, Cole PA. 2008. The structural basis of protein acetylation by the p300/CBP transcriptional coactivator. Nature 451: $846-850$.
Mann BS, Johnson JR, Cohen MH, Justice R, Pazdur R. 2007. FDA approval summary: vorinostat for treatment of advanced primary cutaneous T-cell lymphoma. Oncologist 12: 1247-1252.

Margariti A, Zampetaki A, Xiao Q, Zhou B, Karamariti E, Martin D, Yin X, Mayr M, Li H, Zhang Z, et al. 2010. Histone deacetylase 7 controls endothelial cell growth through modulation of $\beta$-catenin. Circ Res 106: 1202-1211.

Margueron R, Reinberg D. 2011. The Polycomb complex PRC2 and its mark in life. Nature 469: 343-349.

Marks PA. 2010. Histone deacetylase inhibitors: a chemical genetics approach to understanding cellular functions. Biochim Biophys Acta 1799: 717-725.

Marks PA, Breslow R. 2007. Dimethyl sulfoxide to vorinostat: development of this histone deacetylase inhibitor as an anticancer drug. Nat Biotechnol 25: 84-90.

Marks PA, Xu WS. 2009. Histone deacetylase inhibitors: potential in cancer therapy. J Cell Biochem 107: 600-608.

Mikkelsen TS, Ku M, Jaffe DB, Issac B, Lieberman E, Giannoukos G, Alvarez P, Brockman W, Kim TK, Koche RP, et al. 2007. Genome-wide maps of chromatin state in pluripotent and lineage-committed cells. Nature 448: 553-560.

Minucci S, Pelicci PG. 2006. Histone deacetylase inhibitors and the promise of epigenetic (and more) treatments for cancer. Nat Rev Cancer 6: $38-51$.

Montgomery ND, Yee D, Chen A, Kalantry S, Chamberlain SJ, Otte AP, Magnuson T. 2005. The murine polycomb group protein Eed is required for global histone $\mathrm{H} 3$ lysine-27 methylation. Curr Biol 15: 942-947.

Nakagawa Y, Kuwahara K, Harada M, Takahashi N, Yasuno S, Adachi Y, Kawakami R, Nakanishi M, Tanimoto K, Usami S, et al. 2006. Class II HDACs mediate CaMK-dependent signaling to NRSF in ventricular myocytes. J Mol Cell Cardiol 41: 1010-1022.

Olson EN, Backs J, McKinsey TA. 2006. Control of cardiac hypertrophy and heart failure by histone acetylation/deacetylation. Novartis Found Symp 274: $3-12$.

Peart MJ, Smyth GK, van Laar RK, Bowtell DD, Richon VM, Marks PA, Holloway AJ, Johnstone RW. 2005. Identification and functional significance of genes regulated by structurally different histone deacetylase inhibitors. Proc Natl Acad Sci 102: 3697-3702.

Pober JS, Sessa WC. 2007. Evolving functions of endothelial cells in inflammation. Nat Rev Immunol 7: 803-815.

Rada-Iglesias A, Enroth S, Ameur A, Koch CM, Clelland GK, Respuela-Alonso P, Wilcox S, Dovey OM, Ellis PD, Langford CF, et al. 2007. Butyrate mediates decrease of histone acetylation centered on transcription start sites and down-regulation of associated genes. Genome Res 17: 708-719.

Raney BJ, Cline MS, Rosenbloom KR, Dreszer TR, Learned K, Barber GP, Meyer LR, Sloan CA, Malladi VS, Roskin KM, et al. 2011. ENCODE whole-genome data in the UCSC genome browser (2011 update). Nucleic Acids Res 39: D871-D875.

Raynal NJ, Si J, Taby RF, Gharibyan V, Ahmed S, Jelinek J, Estecio MR, Issa JP. 2012. DNA methylation does not stably lock gene expression but instead serves as a molecular mark for gene silencing memory. Cancer Res 72: 1170-1181.

Robinson MD, McCarthy DJ, Smyth GK. 2010. edgeR: a Bioconductor package for differential expression analysis of digital gene expression data. Bioinformatics 26: 139-140.

Roth SY, Denu JM, Allis CD. 2001. Histone acetyltransferases. Annu Rev Biochem 70: $81-120$

Sheridan PL, Mayall TP, Verdin E, Jones KA. 1997. Histone acetyltransferases regulate HIV-1 enhancer activity in vitro. Genes Dev 11: 3327-3340.

Smith BC, Denu JM. 2009. Chemical mechanisms of histone lysine and arginine modifications. Biochim Biophys Acta 1789: 45-57.

Song K, Backs J, McAnally J, Qi X, Gerard RD, Richardson JA, Hill JA, Bassel-Duby R, Olson EN. 2006. The transcriptional coactivator CAMTA2 stimulates cardiac growth by opposing class II histone deacetylases. Cell 125: 453-466.

Subramanian A, Tamayo P, Mootha VK, Mukherjee S, Ebert BL, Gillette MA Paulovich A, Pomeroy SL, Golub TR, Lander ES, et al. 2005. Gene set enrichment analysis: a knowledge-based approach for interpreting genome-wide expression profiles. Proc Natl Acad Sci 102: 15545-15550.

Suzuki H, Gabrielson E, Chen W, Anbazhagan R, van Engeland M, Weijenberg MP, Herman JG, Baylin SB. 2002. A genomic screen for genes upregulated by demethylation and histone deacetylase inhibition in human colorectal cancer. Nat Genet 31: 141-149.

Tanner KG, Landry J, Sternglanz R, Denu JM. 2000. Silent information regulator 2 family of NAD-dependent histone/protein deacetylases generates a unique product, 1-O-acetyl-ADP-ribose. Proc Natl Acad Sci 97: $14178-14182$

Thaler F, Minucci S. 2011. Next generation histone deacetylase inhibitors: the answer to the search for optimized epigenetic therapies? Expert Opin Drug Discov 6: 393-404. 
Rafehi et al.

Wang Z, Zang C, Cui K, Schones DE, Barski A, Peng W, Zhao K. 2009. Genome-wide mapping of HATs and HDACs reveals distinct functions in active and inactive genes. Cell 138: 1019-1031.

Yang C, Wu J, Sinha SH, Neveu JM, Zheng YG. 2012a. Autoacetylation of the MYST lysine acetyltransferase MOF protein. J Biol Chem 287: 34917-34926.

Yang C, Wu J, Zheng YG. 2012b. Function of the active site lysine autoacetylation in Tip60 catalysis. PLOS ONE 7: e32886.

Yao TP, Oh SP, Fuchs M, Zhou ND, Ch'ng LE, Newsome D, Bronson RT, Li E, Livingston DM, Eckner R. 1998. Gene dosage-dependent embryonic development and proliferation defects in mice lacking the transcriptional integrator p300. Cell 93: 361-372.
Yao YL, Yang WM, Seto E. 2001. Regulation of transcription factor YY1 by acetylation and deacetylation. Mol Cell Biol 21: 5979-5991.

Yoshida M, Kijima M, Akita M, Beppu T. 1990. Potent and specific inhibition of mammalian histone deacetylase both in vivo and in vitro by trichostatin A. J Biol Chem 265: 17174-17179.

Zhang Y, Liu T, Meyer CA, Eeckhoute J, Johnson DS, Bernstein BE, Nusbaum C, Myers RM, Brown M, Li W, et al. 2008. Model-based analysis of ChIP-Seq (MACS). Genome Biol 9: R137.

Received October 26, 2013; accepted in revised form April 9, 2014. 


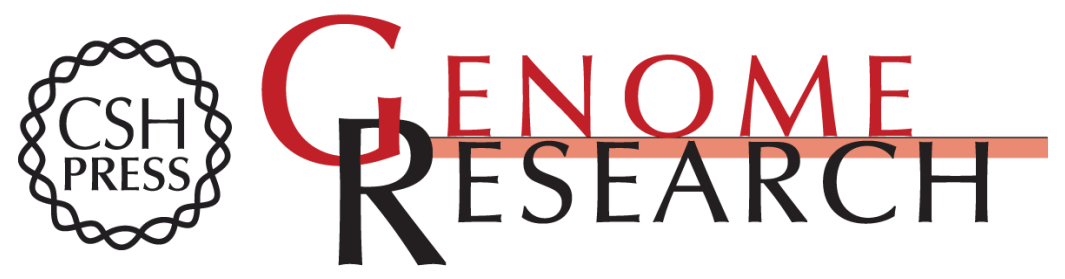

\section{Vascular histone deacetylation by pharmacological HDAC inhibition}

Haloom Rafehi, Aneta Balcerczyk, Sebastian Lunke, et al.

Genome Res. 2014 24: 1271-1284 originally published online April 14, 2014

Access the most recent version at doi:10.1101/gr.168781.113

Supplemental Material

References

Creative

Commons

License

Email Alerting Service
http://genome.cshlp.org/content/suppl/2014/06/05/gr.168781.113.DC1

This article cites 65 articles, 25 of which can be accessed free at: http://genome.cshlp.org/content/24/8/1271.full.html\#ref-list-1

This article is distributed exclusively by Cold Spring Harbor Laboratory Press for the first six months after the full-issue publication date (see

$\mathrm{http}: / /$ genome.cshlp.org/site/misc/terms.xhtml). After six months, it is available under a Creative Commons License (Attribution-NonCommercial 4.0 International), as described at http://creativecommons.org/licenses/by-nc/4.0/.

Receive free email alerts when new articles cite this article - sign up in the box at the top right corner of the article or click here.

\section{Affordable, Accurate Sequencing.}

To subscribe to Genome Research go to:

https://genome.cshlp.org/subscriptions

(C) 2014 Rafehi et al.; Published by Cold Spring Harbor Laboratory Press 